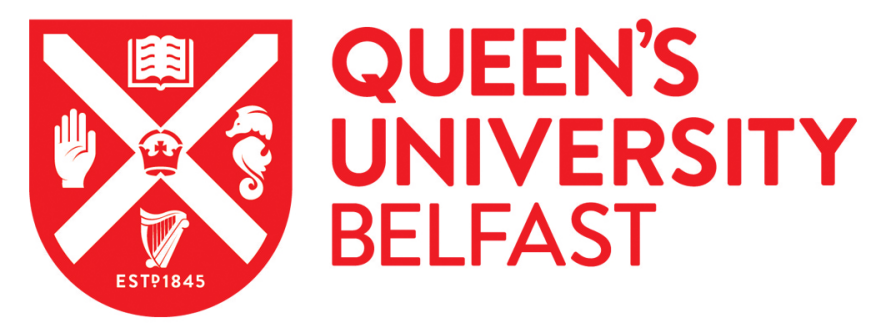

\title{
Ultrahigh-current-density niobium disulfide catalysts for hydrogen evolution
}

Yang, J., Mohmad, A. R., Wang, Y., Fullon, R., Song, X., Zhao, F., Bozkurt, I., Augustin, M., Santos, E. J. G., Shin, H. S., Zhang, W., Voiry, D., Jeong, H. Y., \& Chhowalla, M. (2019). Ultrahigh-current-density niobium disulfide catalysts for hydrogen evolution. Nature Materials, 18(2019), 1309. https://doi.org/10.1038/s41563-0190463-8

Published in:

Nature Materials

Document Version:

Peer reviewed version

Queen's University Belfast - Research Portal:

Link to publication record in Queen's University Belfast Research Portal

Publisher rights

Copyright 2019 Nature Research. This work is made available online in accordance with the publisher's policies. Please refer to any applicable terms of use of the publisher.

\section{General rights}

Copyright for the publications made accessible via the Queen's University Belfast Research Portal is retained by the author(s) and / or other copyright owners and it is a condition of accessing these publications that users recognise and abide by the legal requirements associated with these rights.

Take down policy

The Research Portal is Queen's institutional repository that provides access to Queen's research output. Every effort has been made to ensure that content in the Research Portal does not infringe any person's rights, or applicable UK laws. If you discover content in the Research Portal that you believe breaches copyright or violates any law, please contact openaccess@qub.ac.uk. 
2 Jieun Yang ${ }^{1, \dagger}$, Abdul Rahman Mohmad ${ }^{2, \dagger}$, Yan Wang ${ }^{1}$, Raymond Fullon ${ }^{1}$, Xiuju Song ${ }^{1,3}$, Fang

3 Zhao $^{4}$, Ibrahim Bozkurt ${ }^{1}$, Mathias Augustin ${ }^{5}$, Elton J. G. Santos ${ }^{5 *}$, Hyeon Suk Shin ${ }^{6}$, Damien

4 Voiry $^{7}, \mathrm{Hu}$ Young Jeong ${ }^{8,}$, Manish Chhowalla ${ }^{1,3 * \#}$

5 Affiliations:

$6 \quad{ }^{1}$ Materials Science and Engineering, Rutgers University, 607 Taylor Road, Piscataway, New

7 Jersey 08854, USA.

$8{ }^{\#}$ Current Address: Department of Materials Science \& Metallurgy, University of Cambridge, 27

9 Charles Babbage Road, Cambridge CB3 OFS, UK.

10 2Institute of Microengineering and Nanoelectronics, National University of Malaysia (UKM),

1143600 Bangi, Selangor, Malaysia

12 3SZU-RUT Collaborative Innovation Center for Optoelectronic Science \& Technology, 13 International Collaborative Laboratory of 2D Materials for Optoelectronics Science and

14 Technology of Ministry of Education, College of Optoelectronic Engineering, Shenzhen

15 University, Shenzhen 518060, China.

$16{ }^{4}$ Department of Physics, Princeton University, Jadwin Hall, Princeton New Jersey 08544, USA

17 5chool of Mathematics and Physics, Queen's University Belfast, BT71NN, United Kingdom

$18{ }^{6}$ Department of Chemistry and Department of Energy Engineering, Low-Dimensional Carbon

19 Materials Center, Ulsan National Institute of Science and Technology (UNIST), UNIST-gil 50,

20 Ulsan 44919, Republic of Korea

$21{ }^{7}$ Institut Européen des Membranes (I.E.M.), University of Montpellier, Place Eugène Bataillon,

2234095 Montpellier, France

$23{ }^{8}$ UNIST Central Research Facilities (UCRF) and School of Materials Science and Engineering,

24 UNIST, Ulsan 689-798, Republic of Korea

$25 *$ Correspondence to: e.santos@qub.ac.uk, hulex@unist.ac.kr and mc209@cam.ac.uk

$26{ }^{\dagger}$ These authors contributed equally to this work. 
37 Two-dimensional metallic transition metal dichalcogenides (2D TMDs) such as $1 \mathrm{~T}$ phases of $\mathrm{MoS}_{2}{ }^{1,2}$ and $\mathrm{WS}_{2}{ }^{3}, \mathrm{NbS}_{2}{ }^{4}, \mathrm{TaS}_{2}{ }^{4-6}$ and $\mathrm{VS}_{2}{ }^{7,8}$ have been studied as potentially inexpensive and earth abundant electrocatalysts for the hydrogen revolution reaction (HER). The performance of HER catalysts is typically evaluated in terms of overpotential at which the reaction starts and the Tafel slope - a measure of the over-potential required to increase a reaction by a factor of 10 . The overpotential and Tafel slope values of metallic phases and edges ${ }^{9}$ of 2D TMDs approach those of Pt nanoparticles - the best HER catalyst. However, despite substantial progress the overall current density of 2D TMD catalysts remains orders of magnitude lower $\left(\sim 10-100 \mathrm{~mA}-\mathrm{cm}^{-2}\right)$ than industrial Pt and Ir electrolyzers $\left(>1,000 \mathrm{~mA}-\mathrm{cm}^{-2}\right)^{10,11}$. Here, we report the synthesis of three dimensional (3D) niobium disulfide $\left(\mathrm{Nb}_{1+\mathrm{x}} \mathrm{S}_{2} \text { where } x \text { is } \sim 0.35\right)^{12}$ as a HER catalyst that is capable of evolving hydrogen at current densities of $>5,000 \mathrm{~mA}-\mathrm{cm}^{-2}$ at an overpotential of $\sim 420 \mathrm{mV}$ versus reversible hydrogen electrode (RHE). We find the exchange current density at $0 \mathrm{~V}$ for $2 \mathrm{H}$ phase $\mathrm{Nb}_{1.35} \mathrm{~S}_{2}$ catalysts to be $\sim 0.8 \mathrm{~mA}-\mathrm{cm}^{-2}$ (comparable to that of noble metals), corresponding to a turnover frequency of $\sim 0.2 \mathrm{~s}^{-1}$. We demonstrate a proof of concept electrolyzer based on $2 \mathrm{H} \mathrm{Nb_{1.35 }} \mathrm{S}_{2}$ cathode that is capable of generating current densities of $1000 \mathrm{~mA}-\mathrm{cm}^{-2}$. Our theoretical results reveal that the $\mathrm{Nb}_{1.35} \mathrm{~S}_{2}$ with $\mathrm{Nb}$ terminated surface has free energy for hydrogen adsorption that is close to thermoneutral, facilitating HER. The $\mathrm{Nb}_{1+\mathrm{x}} \mathrm{S}_{2}$ could therefore be a viable non-precious metal catalyst for practical electrolyzers used to generate hydrogen.

Ultra-thin layers of TMD catalysts exhibit improved electrocatalytic performance due to efficient charge injection and transfer to active sites ${ }^{13,14}$. Increasing the conductivity via engineering of metallic phases ${ }^{2,15,16}$ and edges ${ }^{14,17-19}$ also leads to substantial improvement in catalytic

61 properties. To this end, metallic $1 \mathrm{~T}$ phase of semiconducting $\mathrm{MoS}_{2}$ induced by lithium 62 chemistry ${ }^{1,2,20}$ has been widely studied for HER catalysis. Recently, multi-layers of thin metallic 63 TMDs such as $\mathrm{NbS}_{2}{ }^{4}, \mathrm{TaS}_{2}{ }^{5}$, and $\mathrm{VS}_{2}{ }^{7}$ have also been studied for HER. The key advantage of 64 metallic TMDs according to theory is that the entire basal plane is catalytically active for the $65 \mathrm{HER}^{4,21,22}$, unlike in semiconducting $\mathrm{MoS}_{2}$ where only the metallic edges are active ${ }^{9}$. However, 66 in contrast with noble metal catalysts such as Pt nanoparticles, the electronic structure of 
67 atomically thin materials is strongly influenced by local electrochemical reactions. For example, 68 in the case of metallic $1 \mathrm{~T}$ phase $\mathrm{MoS}_{2}$, the adsorption of protons on the surface - the first step in 69 the HER - can dramatically reduce the conductivity of the 2D nanosheets ${ }^{21}$, which can slow 70 down the reaction kinetics and reduce the overall current density. Thus, a fine balance must be 71 achieved between reducing the thickness of catalysts and maintaining metallic nature of 2D 72 materials to maximize catalytic performance.

$\mathrm{NbS}_{2}$ is a layered material that can exist in the hexagonal (2H phase) or rhombohedral (3R) crystal configurations (see Extended Data Fig. 1a,b,d,e). Metallic $2 \mathrm{H}$ phase $\mathrm{NbS}_{2}$ has been predicted to be one of the most efficient electrocatalysts for the HER among the different types of $\mathrm{TMDs}^{22}$. In addition to the $2 \mathrm{H}$ and 3R phases, an unexplored non-layered 3D polytype with $78 \mathrm{Nb}_{1+\mathrm{x}} \mathrm{S}_{2}$ (where $x$ is $\sim 0.35$ ) stoichiometry, first synthesized in $1960\left(\operatorname{Ref}^{12}\right.$ ), consisting of excess niobium strongly bonded to $\mathrm{NbS}_{2}$ layers is also stable (see Extended Data Fig. 1c,f). We find that the exceed $\mathrm{Nb} \mathrm{Nb}_{1+\mathrm{x}} \mathrm{S}_{2}$ phase can be synthesized by adjusting the CVD growth parameters (see Methods). Atomic force microscopy (AFM) image of typical $\mathrm{Nb}_{1+\mathrm{x}} \mathrm{S}_{2}$ crystals synthesized by chemical vapor deposition is shown in Figure 1a. Films of varying thicknesses ranging from 2 $\mathrm{nm}$ to $50 \mathrm{~nm}$ with lateral dimensions of $\sim 0.5-1 \mu \mathrm{m}$ were realized by CVD on substrates such as $\mathrm{SiO}_{2}$ and glassy carbon. We find that the phase of $\mathrm{NbS}_{2}$ is dependent on the thickness of the material (Extended Data Fig. 2a-c). The electron diffraction patterns corresponding to the phases as a function of thickness are provided in Extended Data Fig. 2d,e. In particular, $2 \mathrm{H}-\mathrm{Nb}_{1+\mathrm{x}} \mathrm{S}_{2}$ is predominantly observed in crystals with thickness of less than $\sim 20 \mathrm{~nm}$ while the $3 \mathrm{R}$ phase is primarily stable for thicker samples. High-resolution annular dark field (ADF) cross-sectional STEM images of $\mathrm{Nb}_{1+\mathrm{x}} \mathrm{S}_{2}$ clearly reveal $\mathrm{Nb}$ in both $2 \mathrm{H}$ phase (Figure $1 \mathrm{~b}$ ) and the $3 \mathrm{R}$ phase (Figure 1c). The $\mathrm{d}_{(0002)}$ spacing for the $2 \mathrm{H}$ excess $\mathrm{Nb}$ phase $(6.35 \AA, c=12.60 \AA$ ) was found to 91 be close to the theoretical value of the $\mathrm{Nb}_{1.35} \mathrm{~S}_{2}$ composition. The lower contrast in ADF image of 92 the intercalated $\mathrm{Nb}$ planes is attributed to partial occupation of these sites (occupancy of 0.35 in 93 excess layers versus 1 in the $\mathrm{NbS}_{2} 2 \mathrm{H}$ and $3 \mathrm{R}$ layers). Additional evidence for intercalated $\mathrm{Nb}$ 94 atoms in the form of $Z$ contrast scans of atoms and chemical analyses are provided in Extended 95 Data Fig. 3a,b. X-ray diffraction (XRD) spectrum shown in Extended Data Fig. 3c provides additional evidence for the intercalated hexagonal phase of $\mathrm{NbS}_{2}$. Direct synthesis of intercalated

97 layered compounds with CVD is highly beneficial for preserving the high quality of the material. 
That is, intercalation involving wet chemistry can lead to undesirable local reactions and

99 deterioration of the material properties.

The catalytic properties of $\mathrm{NbS}_{2}$ and other metallic TMDs such as $\mathrm{TaS}_{2}$ and $\mathrm{VS}_{2}$ have been 102 measured in several studies ${ }^{4,5,7}$. The results generally reveal Tafel slopes of $\sim 40 \mathrm{mV}-\mathrm{dec}^{-1}$ and low overpotential values of tens of millivolts vs RHE. For comparison, the overpotential at which HER proceeds for Pt nanoparticles is $0 \mathrm{~V}$ vs RHE with a corresponding Tafel slope of $\sim 30 \mathrm{mV}$ $105 \mathrm{dec}^{-1}$. Despite the promising overpotentials and Tafel slopes achieved with metallic TMD catalysts, the maximum reported current density value has remained around $\sim 100 \mathrm{~mA}-\mathrm{cm}^{-2}$. The current density is limited by the multiple layers of metallic TMDs. That is, in contrast to phase transformed 1T metallic $\mathrm{MoS}_{2}$ nanosheets that are single layered, it is generally challenging to synthesize or exfoliate metal TMDs down to the monolayer. Thus, most metallic $\mathrm{NbS}_{2}$ and $\mathrm{TaS}_{2}$ catalysts are multilayered and therefore electrons injected from the glassy carbon support must overcome the van der Waals gaps between the layers to reach the active sites on the surface. This increases the charge transfer resistance and thus the catalytic activity has been demonstrated to be inversely related to the number of layers in TMDs ${ }^{23}$. In the case of single layers, while the charge transfer kinetics are improved, the current carrying capability is lower and therefore the overall current density that can be achieved is also lower. Furthermore, the recombination of protons with free electrons on the surface of the single layer catalysts (the first step of the reaction) decreases the concentration of free carriers and therefore the conductivity ${ }^{21}$, reducing the kinetics of the HER and lowering the current density.

We have tested the catalytic performance of metallic $2 \mathrm{H} \mathrm{Nb}_{1.35} \mathrm{~S}_{2}$ with improved conductivity via 121 elimination of van der Waals gaps between layers. This $\mathrm{Nb}_{1.35} \mathrm{~S}_{2}$ phase for HER was directly grown at $1273 \mathrm{~K}$ (CVD parameters are described in Methods) on high-quality glassy carbon

123 electrodes. The HER was measured in $0.5 \mathrm{M} \mathrm{H} \mathrm{H}_{2} \mathrm{SO}_{4}$ electrolyte (see Methods for detailed 124 description of measurements). The current density as a function of potential (vs RHE) from $2 \mathrm{H}$, $1253 \mathrm{R} \mathrm{NbS}_{2}$, and excess $\mathrm{Nb} 2 \mathrm{H}$ phase $\mathrm{Nb}_{1.35} \mathrm{~S}_{2}$ along with those from $3 \mathrm{R} \mathrm{Nb}_{1.35} \mathrm{~S}_{2}, 2 \mathrm{H}$ and $1 \mathrm{~T}$ 126 phases of $\mathrm{MoS}_{2}$ and $\mathrm{WS}_{2}$ ref $^{3}, 2 \mathrm{H}$ and $3 \mathrm{R} \mathrm{NbS}_{2}$, and $\mathrm{Pt}$ for comparison are shown in Figure 2a. 127 It can be clearly seen from the polarization curves that the current density for the $2 \mathrm{H} \mathrm{Nb}_{1.35} \mathrm{~S}_{2}$ is 128 exceptionally large, reaching $1000 \mathrm{~mA}-\mathrm{cm}^{-2}$ at $\sim 370 \mathrm{mV}$ and 5,000 $\mathrm{mA}-\mathrm{cm}^{-2}$ at $\sim 420 \mathrm{mV}$. This 
current density is obtained from careful analyses of the catalytic active area. We have examined of numerous scanning electron microscope images to determine the areal coverage of catalyst material on the glassy carbon surface. We found that $20 \% \pm 5 \%$ of the electrode surface is covered by the catalyst particles, see Extended Data Fig. 4. In addition to the areal coverage, we also carefully measured the electrochemical surface area (see Extended Data Fig. 5) to find the roughness factor $(\mathrm{RF}=11 \pm 3)$. Using this value, we were able to accurately determine the active area of the catalyst and use it to calculate the current density. To complement the current density measurements, we measured the actual amount of evolved hydrogen using a gas chromatograph

B) equipped with molecular sieve $5 \AA$ capillary column and a thermal conductivity detector (TCD). The measurements were performed in a gas-tight 3-electrode cell. Ar gas was purged in the cell to remove air. The TCD cell was calibrated using known hydrogen amounts (5\% and $10 \% \mathrm{H}_{2}$ balance Ar certified standard gas). The volume of hydrogen evolved by the $2 \mathrm{H}-\mathrm{Nb}_{1.35} \mathrm{~S}_{2}$ electrodes was measured at two overpotentials. We found that $2 \mathrm{H}-\mathrm{Nb}_{1.35} \mathrm{~S}_{2}$ can evolve $\mathrm{H}_{2}$ up to $150 \mu \mathrm{mol}-\mathrm{h}^{-1}$ and $300 \mu \mathrm{mol}-\mathrm{h}^{-1}$ at $300 \mathrm{mV}$ and $400 \mathrm{mV}$, respectively. When normalizing the performance to the surface area, the rate of $\mathrm{H}_{2}$ evolution reaches $\sim 30 \mathrm{~L}-\mathrm{cm}^{-2}-\mathrm{h}^{-1}$ equivalent to $6 \mathrm{mmol}-\mathrm{h}^{-1}-\mathrm{cm}^{-2}$ at $400 \mathrm{mV}$. the Faradaic efficiency for the HER is typically $100 \%$ and therefore the current density is a direct indication of the amount of hydrogen evolved. Thus, careful measurement of the electrochemical surface area to obtain current density is a good indicator of catalyst performance. To confirm this, we measured the Faradaic efficiency using, $\mathrm{FE}=\frac{2 \mathrm{nF}}{\mathrm{Q}}$ where $n$ is the moles of hydrogen measured from GC, $F$ is the Faraday constant, $\mathrm{Q}$ is the charge obtained from measurements in Figure 2a of the MS $(Q=I \times t$, where $I$ is the current and $t$ is the time). The obtained efficiencies are $96 \%$ and $100 \%$ at $300 \mathrm{mV}$ and $400 \mathrm{mV}$, respectively. Thus, the GC measurements confirm the electrochemical measurements and provide additional evidence for the high performance of $2 \mathrm{H}-\mathrm{Nb}_{1.35} \mathrm{~S}_{2}$.

154 It can be seen from Figure 2b, which provides an expanded view of the low overpotential region 155 in Figure 2a, that the cathodic potential at which the HER starts is less than $100 \mathrm{mV}$ 156 (overpotential of $<150 \mathrm{mV}$ ) for the $2 \mathrm{H} \mathrm{Nb}_{1.35} \mathrm{~S}_{2}$ catalysts. The reaction for metallic $2 \mathrm{H} \mathrm{Nb} \mathrm{Nb}_{1.35} \mathrm{~S}_{2}$ 157 phase starts immediately upon application of the potential and proceeds slowly initially but as the 158 potential is increased, it proceeds rapidly with very high current densities. The Tafel slopes 159 shown in Figure 2c provide additional information about the rate limiting step in the catalytic 
160 performance. Tafel slope values can vary from $30 \mathrm{mV}-\mathrm{dec}^{-1}$ for $\mathrm{Pt}$-indicating that HER is 161 limited by the recombination of adsorbed hydrogens - to $>120 \mathrm{mV}-\mathrm{dec}^{-1}$ where adsorption of 162 protons limits the catalytic activity. It can be seen that the Tafel slope for $2 \mathrm{H}$ phase $\mathrm{Nb}_{1.35} \mathrm{~S}_{2}$ 163 catalysts is $43 \mathrm{mV}-\mathrm{dec}^{-1}$ (and $\sim 38 \mathrm{mV}-\mathrm{dec}^{-1}$ after $i R$ correction) at low overpotentials $(100-120$ $164 \mathrm{mV}$ ), which is comparable to what has been measured for metallic 1T phase $\mathrm{MoS}_{2}$ and $\mathrm{NbS}_{2}$ and suggests that the rate limiting reaction is the desorption of hydrogens. At higher potentials (120 $250 \mathrm{mV}$ ), the Tafel slope increases to $\sim 70 \mathrm{mV}_{-\mathrm{dec}^{-1}}$ (or $65 \mathrm{mV}-\mathrm{dec}^{-1}$ after $i R$ correction), 167 suggesting that hydrogen adsorption or diffusion of protons to active sites limits the reaction. To differentiate between these two mechanisms, we made HER measurements under agitation to increase diffusion of protons and found that the results are largely unchanged. These 170 observations are consistent with theoretical results that show that, unlike Pt, metallic TMD 171 catalysts such as $\mathrm{NbS}_{2}$ possess dilute adsorption of hydrogens on the surface at low potentials but 172 the high activity per site is retained at higher potentials where coverage of adsorbed hydrogens 173 increases ${ }^{4}$. In addition to the overpotential and Tafel slope, we have also measured the number 174 of hydrogen molecules evolved per second (the turnover frequency, TOF) for the catalysts. We 175 have found that the TOF for the $2 \mathrm{H}$ phase $\mathrm{Nb}_{1.35} \mathrm{~S}_{2}$ catalysts to be in excess of $100 \mathrm{~s}^{-1}$ at $280 \mathrm{mV}$. 176 The TOF from this work compares favorably with other reports, as summarized in Figure $2 \mathrm{~d}$. 177 The exchange current density at $0 \mathrm{~V}$ for the $\mathrm{Nb}_{1.35} \mathrm{~S}_{2}$ phase catalysts was found to be $\sim 0.8 \mathrm{~mA}-$ $\mathrm{cm}^{-2}$ which corresponds to a TOF of $0.17 \mathrm{~s}^{-1}$. For comparison, the exchange current density for Pt

179 (111) is $0.5-1 \mathrm{~mA}-\mathrm{cm}^{-2}$ corresponding to TOF of $\sim 1 \mathrm{~s}^{-1}$ (Ref ${ }^{9}$ ) and for metallic 2D TMDs the 180 values are $0.02 \mathrm{~mA}-\mathrm{cm}^{-2}$ and $0.043 \mathrm{~s}^{-1}\left(\operatorname{Ref}^{3}\right)$, suggesting that the turnover for hydrogen 181 evolution is high for $2 \mathrm{H}$ phase $\mathrm{Nb}_{1.35} \mathrm{~S}_{2}$ catalysts. Summary of the obtained values is provided in 182 Extended Data Table 1. Impedance measurements on $2 \mathrm{H}$ and $3 \mathrm{R} \mathrm{Nb}_{1.35} \mathrm{~S}_{2}$ are shown in Figure $3 \mathrm{a}$. It can be seen that the series resistance for the $2 \mathrm{H}$ phase $\mathrm{Nb}_{1.35} \mathrm{~S}_{2}$ obtained at $1 \mathrm{MHz}$ where the phase angle is close to 186 zero is $3.5 \Omega$ due to its high electrical conductivity and indicating good contact with glassy 187 carbon electrode. The charge transfer resistance is $7.4 \Omega$, facilitating charge injection and 188 transport to active sites. In contrast, the $3 \mathrm{R} \mathrm{Nb}_{1.35} \mathrm{~S}_{2}$ shows higher resistances and diffusion 189 limited activity. This is in agreement with our observations that the $3 \mathrm{R}$ phase is less conducting 190 and is stable at higher film thicknesses. Finally, we have measured the electrochemical stability 
191 of the electrodes by carrying out over 10000 cycles. The high current density shows remarkable

192 stability with negligible difference in polarization curves and overpotential values after 10,000 193 cycles (Figure 3b). The above experimental results suggest that intercalation of $\mathrm{Nb}$ between $2 \mathrm{H}$ 194 phase $\mathrm{NbS}_{2}$ layers to realize $\mathrm{Nb}_{1.35} \mathrm{~S}_{2}$ allow realization of practical current densities of $>5,000$ $195 \mathrm{~mA}-\mathrm{cm}^{-2}$ - making them potentially useful alternatives to Pt and Ir. To translate the high current densities of $2 \mathrm{H}$ phase $\mathrm{Nb}_{1.35} \mathrm{~S}_{2}$ catalysts into practical device, we fabricated a proof of concept

197 two electrode electrolyzer for water splitting. The device shown in Figure 3c consists of $2 \mathrm{H}$ $198 \mathrm{Nb}_{1.35} \mathrm{~S}_{2}$ on glassy carbon cathode and a commercial Pt anode. The measurements were carried out at room temperature in $0.5 \mathrm{M} \mathrm{H}_{2} \mathrm{SO}_{4}$. The device characteristics are plotted in Figure $3 \mathrm{~d}$, which show that the reaction for the $2 \mathrm{H} \mathrm{Nb} \mathrm{Nb}_{1.35} \mathrm{~S}_{2}$ starts around $1.3 \mathrm{~V}$ and the current densities reach $1000 \mathrm{~mA}-\mathrm{cm}^{-2}$ at $2.0 \mathrm{~V}$. Proof of concept electrolyzers of this type typically report current densities of $10-100 \mathrm{~mA}-\mathrm{cm}^{-2}$ at similar potential values ${ }^{24}$.

To elucidate the fundamental mechanisms responsible for the catalytic performance of $2 \mathrm{H}$ $\mathrm{Nb}_{1.35} \mathrm{~S}_{2}$, we calculated the thermodynamics of the limiting reaction - the adsorption of hydrogen on the catalyst surface using density functional theory (DFT) including van der Waals interactions. It is well known that the best HER catalysts possess $\Delta G \sim 0$ (that is, thermoneutral condition) so that there is a driving force for hydrogen adsorption on the active site but the binding energy is low to allow efficient hydrogen evolution. The results of the calculations are shown in Figure 4. Our theoretical results suggest that both the $\mathrm{Nb}$ and $\mathrm{S}$ terminations are stable

211 for the $\mathrm{Nb}_{1.35} \mathrm{~S}_{2}$ phases. We have observed intercalated $\mathrm{Nb}$ terminated surface by STEM imaging 212 (see Extended Data Fig. 3d). It can be seen in Figure 4a that the free energy for hydrogen 213 adsorption for the $2 \mathrm{H} \mathrm{Nb}_{1.35} \mathrm{~S}_{2}$ is close to being thermoneutral $(\sim 0.11 \mathrm{eV})$ when the surface is 214 terminated by $\mathrm{Nb}$ under 0.25 monolayer coverage (Figure $4 \mathrm{~b}$ ). In contrast, the free energy of 215 adsorbed hydrogen is $\sim 1 \mathrm{eV}$ when the surface is terminated by sulfur in $2 \mathrm{H} \mathrm{Nb}_{1.35} \mathrm{~S}_{2}$. The 216 calculations also reveal that the reaction is localized to the surface of the catalysts, as indicated 217 by the charge density diagrams in Figure $4 \mathrm{c}$. The better HER properties of the $2 \mathrm{H} \mathrm{N} \mathrm{Nb}_{1.35} \mathrm{~S}_{2}$

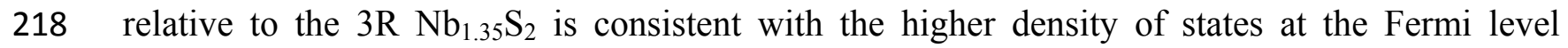
219 (Figure 4e,f), which translates into higher measured conductivity and better charge transfer 220 kinetics. Thus, our work provides new insight into materials design for achieving high current densities with non-precious metal catalysts. 


\section{Figure captions}

224 Figure 1 | Images of $\mathbf{N b}_{1+\mathrm{x}} \mathbf{S}_{2}$ crystals and atomic structure. a, Atomic force microscopy 225 image of a grown $\mathrm{Nb}_{1+\mathrm{x}} \mathrm{S}_{2}(x \sim 0.35)$ crystals on high quality glassy carbon (scale bar $\left.=1 \mu \mathrm{m}\right)$. b, 226 Cross-sectional ADF STEM image of $2 \mathrm{H}$ phase $\mathrm{Nb}_{1.35} \mathrm{~S}_{2}$ and $3 \mathrm{R}$ phase $\mathrm{Nb}_{1+\mathrm{x}} \mathrm{S}_{2}$, c. The dashed 227 white rectangle represents the unit cell of the structure and the corresponding ball and stick 228 model of the unit cell is shown on the right. The red dashed rectangles in the STEM image and 229 the schematic indicate the positions of the intercalated $\mathrm{Nb}$. Since these sites are partially occupied, the contrast of these planes is lower than of the fully occupied $\mathrm{Nb}$ sites. The arrows correlate the locations of the atoms in the STEM image with the atoms in the unit cell. The dark green arrows and spheres in the schematic indicate fully occupied $\mathrm{Nb}$ sites and light green arrows and spheres in unit cell indicate partially occupied $\mathrm{Nb}$ atoms. $\mathrm{Z}$. A. refers to zone axis of the crystal structure. Scale bar $=5 \AA$.

Figure 2 | HER catalytic activities of different TMDs. a, Polarization curves for $2 \mathrm{H}-\mathrm{MoS}_{2}$, $1 \mathrm{~T}-\mathrm{MoS}_{2}$ and $\mathrm{WS}_{2}, 2 \mathrm{H}-\mathrm{Nb}_{1.35} \mathrm{~S}_{2}, 3 \mathrm{R}-\mathrm{Nb}_{1.35} \mathrm{~S}_{2}, 2 \mathrm{H}-\mathrm{NbS}_{2}$ and $3 \mathrm{R} \mathrm{NbS}_{2}$ and $\mathrm{Pt}$ measured in $0.5 \mathrm{M}$ $\mathrm{H}_{2} \mathrm{SO}_{4}$ with a scan rate of $5 \mathrm{mVs}^{-1}$. b, Expanded view of the low overpotential region in a. The reaction starts immediately upon application of voltage, indicating that the onset potential of $2 \mathrm{H}$ $\mathrm{Nb}_{1.35} \mathrm{~S}_{2}$ is $<100 \mathrm{mV}$ and overpotential is $150 \mathrm{mV}$. c, Tafel slopes of different catalysts obtained from polarization curves in a. $2 \mathrm{H}-\mathrm{Nb}_{1.35} \mathrm{~S}_{2}$ shows slope of $43 \mathrm{mV}-\mathrm{dec}^{-1}\left(38 \mathrm{mV}-\mathrm{dec}^{-1}\right.$ after $i R$ correction) at low overpotentials $\left(100-130 \mathrm{mV}\right.$, green) and $70 \mathrm{mV}-\mathrm{dec}^{-1}\left(65 \mathrm{mV}-\mathrm{dec}^{-1}\right.$ after $i R$ correction) at high overpotentials $\left(130-200 \mathrm{mV}\right.$, red). d, TOF values of the $2 \mathrm{H}-\mathrm{Nb}_{1.35} \mathrm{~S}_{2}$ (black line) and other $\mathrm{MoS}_{2}$-based catalysts reported in the literature ${ }^{25,26} \cdot \mathrm{MoS}_{2}$ basal planes with sulfur vacancies (blue) ${ }^{27}$, strained $\mathrm{MoS}_{2}$ basal planes with sulfur vacancies (green) ${ }^{27}$ and $\mathrm{MoS}_{2}$ with low charge transfer resistance, $R_{C}$ (magenta) ${ }^{15}$.

Figure 3 | Electrochemical impedance spectroscopy (EIS), electrochemical stability of $\mathrm{Nb}_{1.35} \mathrm{~S}_{2}$ and proof of concept electrolyzer demonstration. a, Nyquist plots of $2 \mathrm{H}$ phase (red curve) and 3R phase $\mathrm{Nb}_{1.35} \mathrm{~S}_{2}$. Magnification of $2 \mathrm{H}-\mathrm{Nb}_{1.35} \mathrm{~S}_{2}$ plot is shown in the inset. The plots (dash line) were fitted using an equivalent circuit to extract the series and charge transfer resistances. b, Polarization curves of $2 \mathrm{H}-\mathrm{Nb}_{1.35} \mathrm{~S}_{2}$ before (black curve) and after (red curve) 10,000 cycles. The insets show the percentage of change in overpotential. The error bars are 
254 obtained from at least five measurements. c, Photograph of the two electrode electrolyzer device 255 consisting of commercial $\mathrm{Pt}$ anode and $2 \mathrm{H}-\mathrm{Nb}_{1.35} \mathrm{~S}_{2}$ cathode. d, Polarization curves of water 256 electrolysis showing current density of $1000 \mathrm{~mA}-\mathrm{cm}^{-2}$.

258 Figure 4 | Thermodynamic stability and free-energy calculations for hydrogen evolution for $2592 \mathbf{H}-\mathbf{N b}_{1.35} \mathbf{S}_{2}$ and $3 \mathbf{R}-\mathbf{N b}_{1.35} \mathbf{S}_{2}$ phases. a, The free-energy diagram for hydrogen evolution at 260 standard conditions ( 1 bar of $\mathrm{H}_{2}$ and $\mathrm{pH}=0$ at $300 \mathrm{~K}$ ). The energies of the intermediate states are 261 calculated using BEEF-vdW functional as described in the Methods. A coverage of 0.25 ML was 262 used for all calculations. b, Optimized geometries for S- and Nb-terminated surfaces of $2 \mathrm{H}$ $263 \mathrm{Nb}_{1.35} \mathrm{~S}_{2}$ and $3 \mathrm{R}-\mathrm{Nb}_{1.35} \mathrm{~S}_{2}$ phases. $\mathrm{c}$, Charge density difference for $\mathrm{H}$ adsorbed on top of $\mathrm{Nb}-$ 264 terminated $2 \mathrm{H}-$ and $3 \mathrm{R}-\mathrm{Nb}_{1.35} \mathrm{~S}_{2}$ phases. Most of the charge is localized on the surface, with clear 265 differences between $2 \mathrm{H}$ - and $3 \mathrm{R}-\mathrm{Nb}_{1.35} \mathrm{~S}_{2}$ phases with the former having larger magnitudes. e-f, 266 Density of states (DOS) per atom for Nb-terminated $2 \mathrm{H}$ - and $3 \mathrm{R}-\mathrm{Nb}_{1.35} \mathrm{~S}_{2}$ phases projected on 267 different $\mathrm{Nb}$ sites. Surface $\mathrm{Nb}$, inner $\mathrm{Nb}$ and deep bulk $\mathrm{Nb}$ atoms are shown in red, blue and 268 orange, respectively. For a better contrast between the different Nb's atoms, the DOS of surface $269 \mathrm{Nb}$ atoms is highlighted with a filled faint red. Fermi level is set to $0 \mathrm{eV}$. 
272 Figure 1:

273

274

275

276
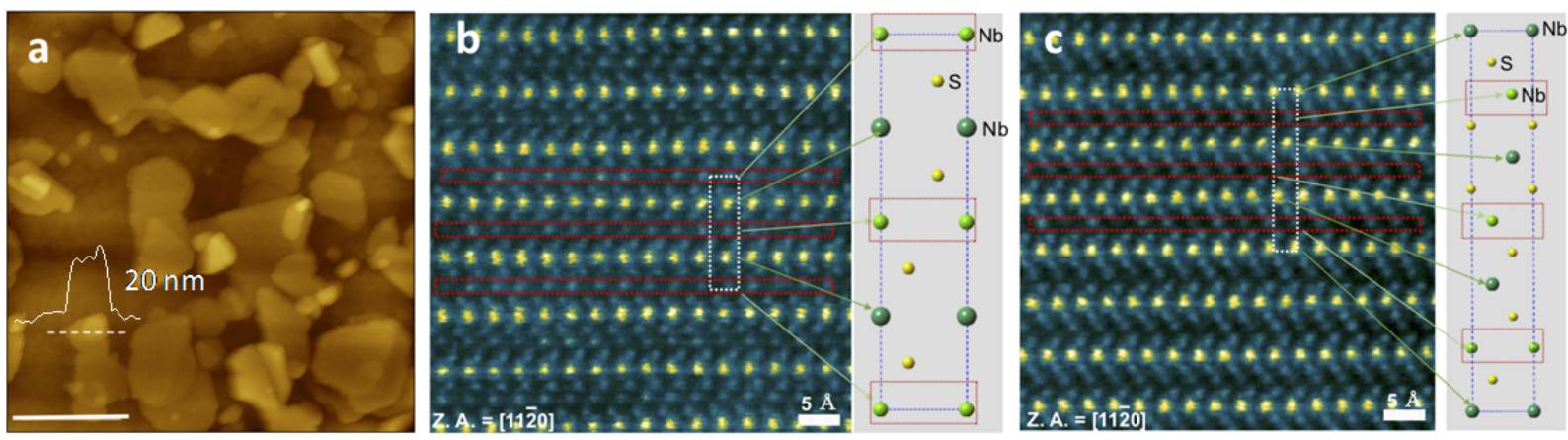

277

278

279

280

281

282

283

284

285

286

287

288

289

290

291

292

293

294

295

296 
Figure 2

a
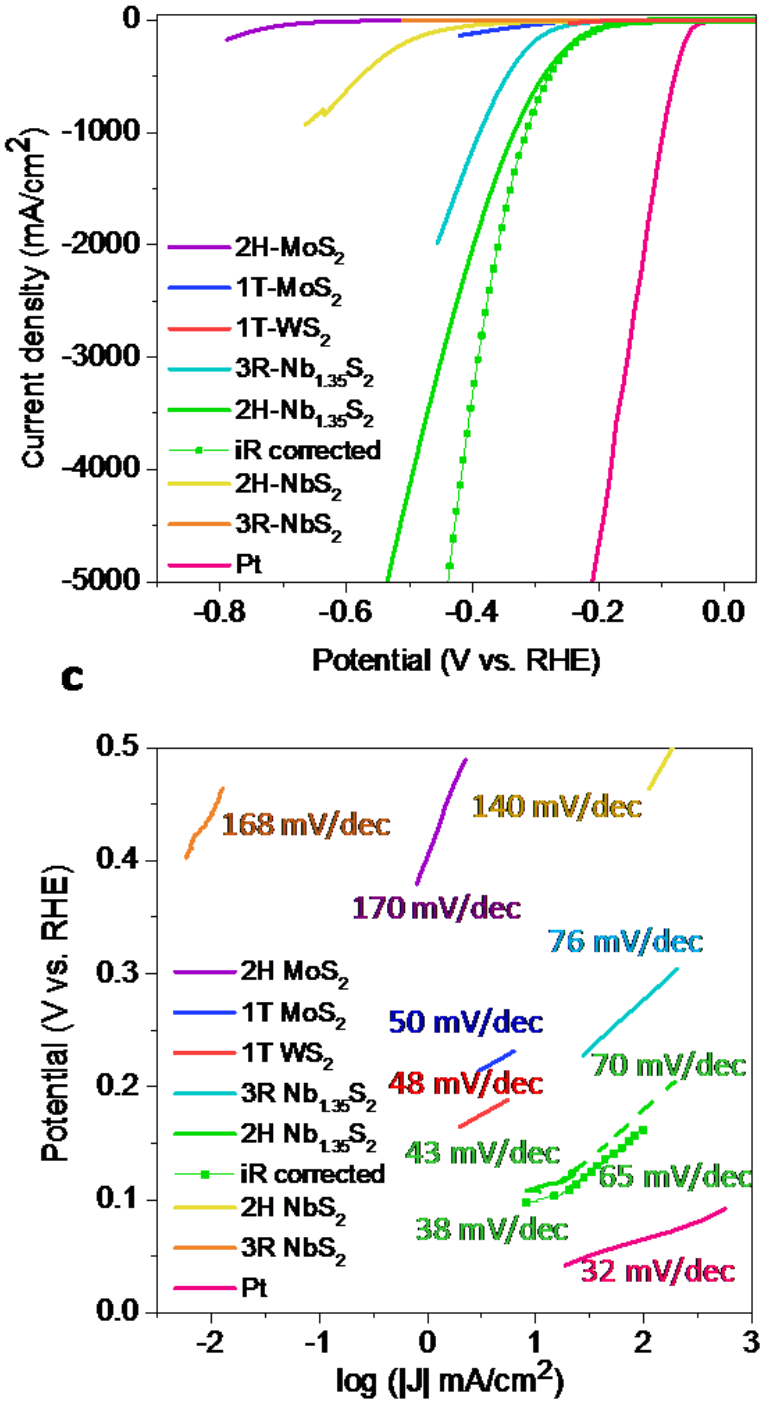

b
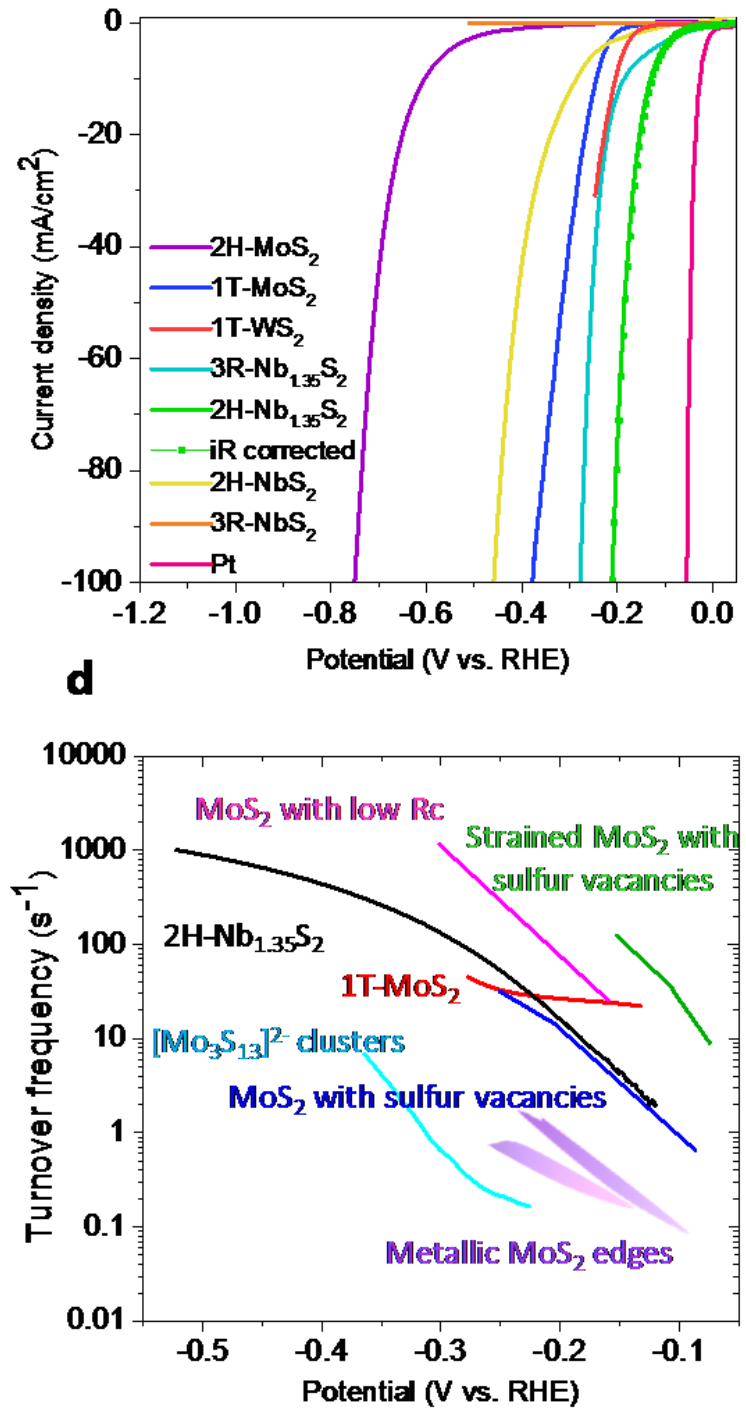
Figure 3

302

303

a

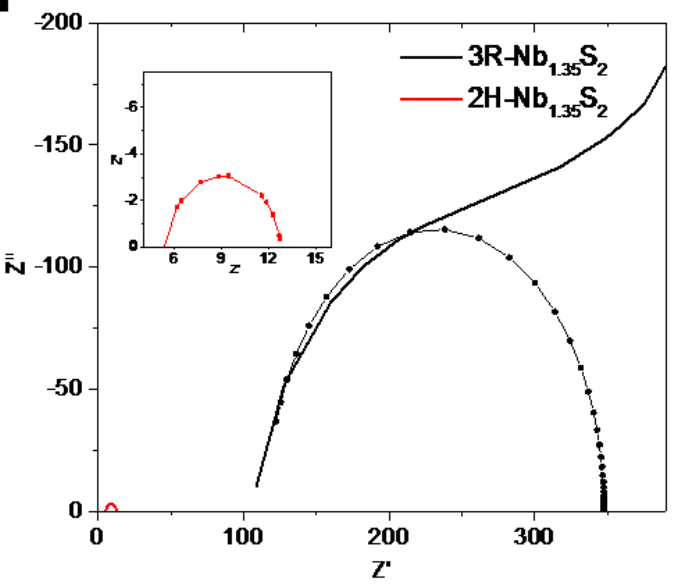

C

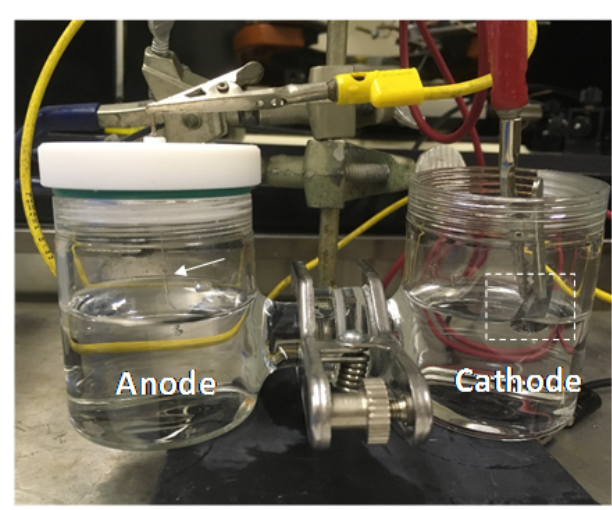

b
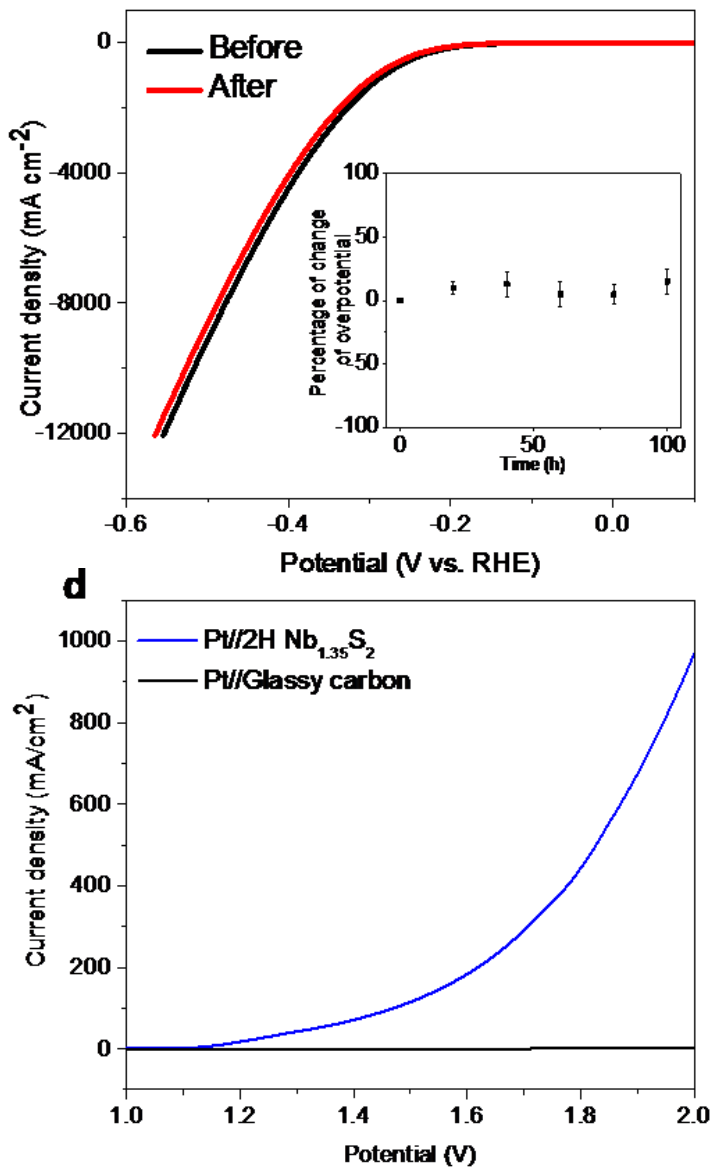

304 
310

\section{Figure 4}

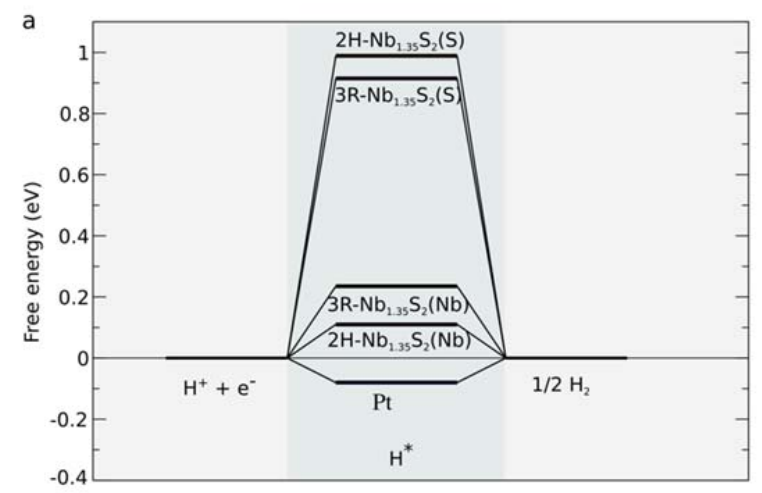

b

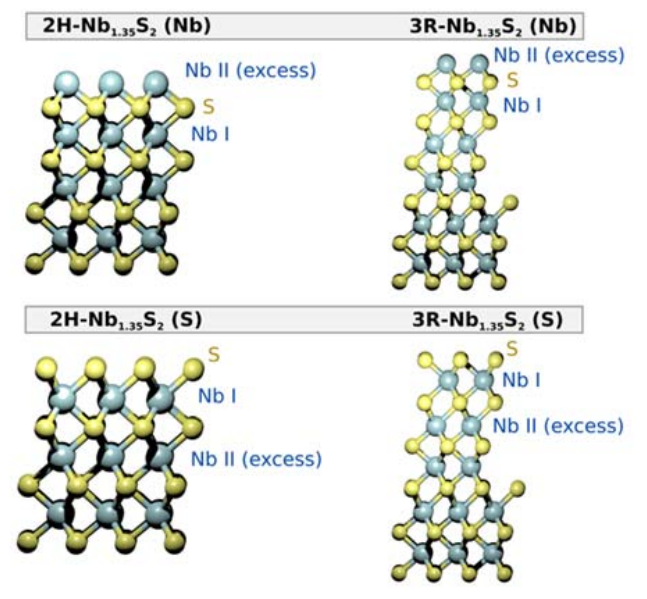

311

312

313

314

315

316

317

318

319

320

321

322

323

324

325

326

327 c

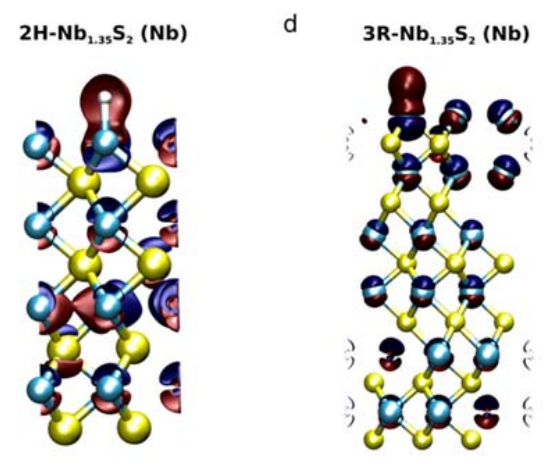

e

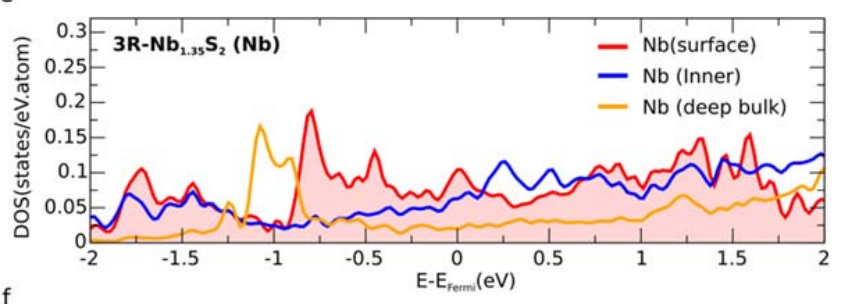

f

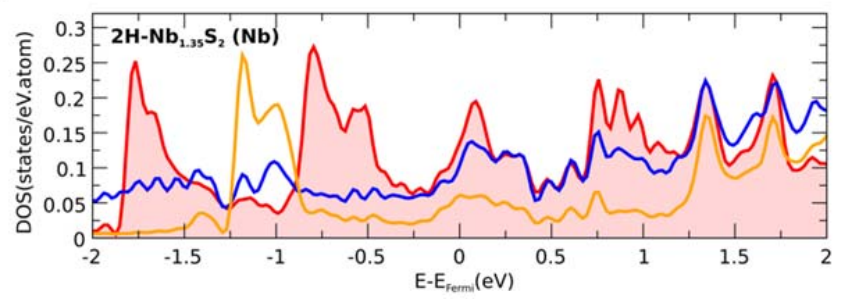




\section{References}

1. Lukowski, M. A. et al. Enhanced Hydrogen Evolution Catalysis from Chemically Exfoliated Metallic $\mathrm{MoS}_{2}$ Nanosheets. J. Am. Chem. Soc. 135, 10274-10277 (2013).

2. Voiry, D. et al. Conducting MoS2 Nanosheets as Catalysts for Hydrogen Evolution Reaction. Nano Lett. 13, 6222-6227 (2013).

3. Voiry, D. et al. Enhanced catalytic activity in strained chemically exfoliated $\mathrm{WS}_{2}$ nanosheets for hydrogen evolution. Nat. Mater. 12, 850 (2013).

4. Liu, Y. et al. Self-optimizing, highly surface-active layered metal dichalcogenide catalysts for hydrogen evolution. Nat. Energy 2, 17127 (2017).

5. Shi, J. et al. Two-dimensional metallic tantalum disulfide as a hydrogen evolution catalyst. Nat. Commun. 8, 958 (2017).

6. Li, H. et al. Atomic-Sized Pores Enhanced Electrocatalysis of TaS2 Nanosheets for Hydrogen Evolution. Adv. Mater. 28, 8945-8949 (2016).

7. Yuan, J. et al. Facile Synthesis of Single Crystal Vanadium Disulfide Nanosheets by Chemical Vapor Deposition for Efficient Hydrogen Evolution Reaction. Adv. Mater. 27, 5605-5609 (2015).

8. Chia, X., Ambrosi, A., Lazar, P., Sofer, Z. \& Pumera, M. Electrocatalysis of layered Group 5 metallic transition metal dichalcogenides ( $\mathrm{MX} 2, \mathrm{M}=\mathrm{V}, \mathrm{Nb}$, and Ta; $\mathrm{X}=\mathrm{S}, \mathrm{Se}$, and Te). $J$. Mater. Chem. A 4, 14241-14253 (2016).

9. Jaramillo, T. F. et al. Identification of Active Edge Sites for Electrochemical H2 Evolution from MoS2 Nanocatalysts. Science 317, 100-102 (2007). 
350 10. Zhigang, S., Baolian, Y. \& Ming, H. Bifunctional electrodes with a thin catalyst layer for 351 'unitized' proton exchange membrane regenerative fuel cell. J. Power Sources 79, 82-85 352 (1999).

353 11. Altmann, S., Kaz, T. \& Friedrich, K. A. Bifunctional electrodes for unitised regenerative 354 fuel cells. Electrochimica Acta 56, 4287-4293 (2011).

355 12. Jellinek, F., Brauer, G. \& Müller, H. Molybdenum and Niobium Sulphides. Nature 185, $356 \quad 376(1960)$.

357 13. Merki, D. \& Hu, X. Recent developments of molybdenum and tungsten sulfides as 358 hydrogen evolution catalysts. Energy Environ. Sci. 4, 3878-3888 (2011).

359 14. Benck, J. D., Hellstern, T. R., Kibsgaard, J., Chakthranont, P. \& Jaramillo, T. F. 360 Catalyzing the Hydrogen Evolution Reaction (HER) with Molybdenum Sulfide 361 Nanomaterials. ACS Catal. 4, 3957-3971 (2014).

362 15. Voiry, D. et al. The role of electronic coupling between substrate and 2D $\mathrm{MoS}_{2}$ 363 nanosheets in electrocatalytic production of hydrogen. Nat. Mater. 15, 1003 (2016).

364 16. Yin, Y. et al. Contributions of Phase, Sulfur Vacancies, and Edges to the Hydrogen 365 Evolution Reaction Catalytic Activity of Porous Molybdenum Disulfide Nanosheets. J. Am. 366 Chem. Soc. 138, 7965-7972 (2016).

367 17. Kibsgaard, J., Chen, Z., Reinecke, B. N. \& Jaramillo, T. F. Engineering the surface 368 structure of $\mathrm{MoS}_{2}$ to preferentially expose active edge sites for electrocatalysis. Nat. Mater. $369 \quad$ 11, $963(2012)$.

370 18. Kong, D. et al. Synthesis of MoS2 and MoSe2 Films with Vertically Aligned Layers.

$371 \quad$ Nano Lett. 13, 1341-1347 (2013). 
372 19. Tsai, C., Abild-Pedersen, F. \& Nørskov, J. K. Tuning the MoS2 Edge-Site Activity for 373 Hydrogen Evolution via Support Interactions. Nano Lett. 14, 1381-1387 (2014).

374 20. Eda, G. et al. Photoluminescence from Chemically Exfoliated MoS2. Nano Lett. 11, $375 \quad 5111-5116(2011)$

376 21. Pan, H. Metal Dichalcogenides Monolayers: Novel Catalysts for Electrochemical 377 Hydrogen Production. Sci. Rep. 4, 5348 (2014).

378 22. Tsai, C., Chan, K., Nørskov, J. K. \& Abild-Pedersen, F. Theoretical insights into the 379 hydrogen evolution activity of layered transition metal dichalcogenides. Surf. Sci. 640, $133-$ $380 \quad 140(2015)$.

381 23. Yu, Y. et al. Layer-Dependent Electrocatalysis of MoS2 for Hydrogen Evolution. Nano 382 Lett. 14, 553-558 (2014).

383 24. Han, N. et al. Nitrogen-doped tungsten carbide nanoarray as an efficient bifunctional 384 electrocatalyst for water splitting in acid. Nat. Commun. 9, 924 (2018).

385 25. Kibsgaard, J., Jaramillo, T. F. \& Besenbacher, F. Building an appropriate active-site 386 motif into a hydrogen-evolution catalyst with thiomolybdate $\left[\mathrm{Mo}_{3} \mathrm{~S}_{13}\right]^{2-}$ clusters. Nat. Chem. $387 \quad 6,248(2014)$.

388 26. Xie, J. et al. Defect-Rich MoS2 Ultrathin Nanosheets with Additional Active Edge Sites 389 for Enhanced Electrocatalytic Hydrogen Evolution. Adv. Mater. 25, 5807-5813 (2013).

390 27. Li, H. et al. Activating and optimizing $\mathrm{MoS}_{2}$ basal planes for hydrogen evolution through 391 the formation of strained sulphur vacancies. Nat. Mater. 15, 48 (2016). 
Acknowledgments: MC, JY acknowledge financial support from AFOSR FA9550-16-1-0289.

398 MC, YW acknowledge support from NSF ECCS-1608389. MC and XS acknowledge support

399 from Shenzhen Peacock Plan (Grant No. KQTD2016053112042971). MC and ARM

400 acknowledge financial support from the Ministry of Higher Education Malaysia. HYJ

401 acknowledges the support from Creative Materials Discovery Program through the National

402 Research Foundation of Korea (NRF-2016M3D1A1900035). E.J.G.S. acknowledges the use of

403 computational resources from the UK national high-performance computing service (ARCHER)

404 for which access was obtained via the UKCP consortium (EPSRC grant ref EP/K013564/1); the

405 UK Materials and Molecular Modelling Hub for access to THOMAS supercluster, which is 406 partially funded by EPSRC (EP/P020194/1). The Queen's Fellow Award through the grant

407 number M8407MPH, the Enabling Fund (A5047TSL), and the Department for the Economy

408 (USI 097) are also acknowledged.

409

\section{Author Contributions}

411 MC conceived the idea and supervised the project. JY and ARM designed the experiments with 412 guidance from MC. JY performed the electrochemical measurements and analyses with advice 413 from RF and $\mathrm{DV}$. ARM synthesized the $\mathrm{Nb}_{1.35} \mathrm{~S}_{2}$ samples and characterized them. YW made the 414 devices for HER measurements and made electrical measurements. XS and IB made $\mathrm{NbS}_{2}$ 415 samples and characterized them with the help of FZ. HYJ prepared the FIB samples, performed 416 the STEM analyses on the samples. MA and EJGS provided theoretical insight for the 417 experimental results. MC, HYJ, JY, DV, RF and HS analyzed the data. MC wrote the paper with 418 JY and all of the authors edited the manuscript before submission. 
432 Growth of $2 \mathbf{H}-\mathbf{N b}_{1+\mathrm{x}} \mathbf{S}_{2}$ and $3 \mathbf{R}-\mathbf{N b}_{1+\mathrm{x}} \mathbf{S}_{2}: \mathrm{Nb}_{1+\mathrm{x}} \mathrm{S}_{2}$ growth was achieved under low pressure in a 433 horizontal furnace (Lindberg/Blue M) with 1-inch diameter quartz tube. Two small quartz tubes 434 (diameter $\sim 9 \mathrm{~mm}$ ) loaded with niobium chloride $\left(\mathrm{NbCl}_{5}\right.$, Alfa Aesar, 99.9\%) and sulfur powder 435 (Alfa Aesar, 99.5\%), were placed upstream of the furnace as shown in Extended Data Fig. 6. The 436 substrates $\left(\mathrm{SiO}_{2} / \mathrm{Si}\right.$ and glassy carbon) were placed face up above an alumina boat in the center 437 zone of the furnace. The tube was initially pumped to a base pressure of 20 Torr for $30 \mathrm{~min}$. The 438 furnace was heated up to $850^{\circ} \mathrm{C}$ with a ramp rate of $55^{\circ} \mathrm{C} / \mathrm{min}$ with a flow of $90 \mathrm{sccm}$ Ar. Then, 439 the furnace was heated up to $1000{ }^{\circ} \mathrm{C}$ with a ramp rate of $6{ }^{\circ} \mathrm{C} / \mathrm{min}$ under a flow of $90 \mathrm{sccm}$ $440 \mathrm{H}_{2} / \mathrm{Ar}\left(10 \% \mathrm{H}_{2}\right.$ in $\left.\mathrm{Ar}\right)$. The $\mathrm{NbCl}_{5}$ was sublimated via a heating belt at $260 \sim 300{ }^{\circ} \mathrm{C}$ within $5 \mathrm{~min}$ 441 when the furnace reached to $1000{ }^{\circ} \mathrm{C}$ as indicated by the heating cycle shown in Extended Data 442 Fig. 7. After growth for $8 \mathrm{~min}$ at $1000{ }^{\circ} \mathrm{C}$, the whole system was naturally cooled down to room 443 temperature.

445 Synthesis of $\mathbf{2 H}-\mathrm{NbS}_{2}: 2 \mathrm{H}-\mathrm{NbS}_{2}$ was synthesized by CVD using niobium oxide $\left(\mathrm{Nb}_{2} \mathrm{O}_{5}, 99.9 \%\right.$ 446 Sigma-Aldrich) mixed with alkali halide (potassium iodine, KI) and sulfur powder (99.5\%, Alfa 447 Aesar). Since niobium oxide has a high melting point, alkali halide is used to create a new 448 eutectic point for the reaction to produce more volatile oxides. ${ }^{28}$ The mixture of $150 \mathrm{mg}$ of $449 \mathrm{Nb}_{2} \mathrm{O}_{5}$ and $100 \mathrm{mg}$ of $\mathrm{KI}$ powders in alumina boat was loaded at the center of the tube furnace 450 and $\mathrm{SiO}_{2}$ substrates were placed above the powder with its polished side facing down. $100 \mathrm{mg}$ of $451 \mathrm{~S}$ powder was loaded in the upstream region of the tube. Then, $80 \mathrm{sccm}$ carrier gas $\left(10 \% \mathrm{Of} \mathrm{H}_{2}\right.$ 452 in Ar) was introduced for $20 \mathrm{~min}$ to remove oxygen in the furnace. The furnace was heated with 453 a ramp rate of $33{ }^{\circ} \mathrm{C} / \mathrm{min}$ to the growth temperatures $\left(1000{ }^{\circ} \mathrm{C}\right)$ and held at $1000{ }^{\circ} \mathrm{C}$ for $30 \mathrm{~min}$ 454 before cooling down. The upstream region reached $200{ }^{\circ} \mathrm{C}$ during the growth. The thin $2 \mathrm{H} \mathrm{NbS}_{2}$ 455 crystals and their corresponding Raman spectrum are shown in Extended Data Fig. 8a,b.

457 Synthesis of $3 R-N_{2}$ : $3 R-N_{2}$ crystals were grown by a chemical vapor transport (CVT) 458 method which has been employed to prepare other layered compounds. ${ }^{29}$ Prior to crystal growth, 459 a quartz tube containing high purity source $(\mathrm{Nb} 99.99 \%$ and $\mathrm{S} 99.99 \%$ with a molar ratio of $\mathrm{Nb}: \mathrm{S}$ 460 is 1:2) was evacuated at $10^{-6}$ Torr and sealed. The sealed quartz tube was then inserted into the 461 tube furnace. The furnace was heated up to $900{ }^{\circ} \mathrm{C}$ with a ramp rate of $3{ }^{\circ} \mathrm{C} / \mathrm{min}$. The reaction 
time was $18 \mathrm{~h}$ at $900{ }^{\circ} \mathrm{C}$ and the furnace was cooled down naturally. The CVT grown 3R crystals and the corresponding Raman spectrum are shown in Extended Data Fig. 8c,d.

Electrochemical measurements: Electrochemical measurements were performed in a three466 electrode cell using a Versa Stat 3 potentiostat from Princeton Applied research. All measurements were made in $0.5 \mathrm{M} \mathrm{H}_{2} \mathrm{SO}_{4}$ electrolyte purged with Ar gas. A saturated calomel electrode (Pine Instrument) and glassy carbon were used as the reference electrode and counter electrode, respectively. Extended Data Fig. 9 shows the polarization curves obtained from $2 \mathrm{H}$ $\mathrm{Nb}_{1.35} \mathrm{~S}_{2}$ using platinum and carbon counter electrode. No noticeable difference was observed, and this excludes any Pt contamination during the measurements. The glassy carbon plate (Ted 472 pella) loaded with $3 \mathrm{R}$ - and $2 \mathrm{H}-\mathrm{Nb}_{1.35} \mathrm{~S}_{2}$ was used as a working electrode. $3 \mathrm{R}-\mathrm{NbS}_{2}$ was dispersed 473 into toluene and sonicated for $1 \mathrm{~h}$. The solution was deposited onto glassy carbon electrode $(0.1$ $474 \mathrm{mg} / \mathrm{cm}^{2}$ ) and dried. $1 \mathrm{~T}-\mathrm{MoS}_{2}$ was prepared by the exfoliation of $2 \mathrm{H}-\mathrm{MoS}_{2}$ by $\mathrm{n}-\mathrm{BuLi}$ following 475 literature. ${ }^{20} 1 \mathrm{~T}-\mathrm{MoS}_{2}$ solution was loaded onto glassy carbon electrode $\left(4 \mu \mathrm{g} / \mathrm{cm}^{2}\right)$ and $2 \mathrm{H}-\mathrm{MoS}_{2}$ 476 powder is dispersed into the mixed solution with DI water/IPA (the volume ratio 4:1) and 477 sonicated for $1 \mathrm{~h}$ to drop onto the glassy carbon electrode. All polarization curves were measured 478 at the scan rate of $5 \mathrm{mVs}^{-1}$. All potentials are referenced to RHE. In $0.5 \mathrm{M} \mathrm{H}_{2} \mathrm{SO}_{4}$, $479 \mathrm{E}(\mathrm{RHE})=\mathrm{E}(\mathrm{SCE})+0.254 \mathrm{~V}$. Impedance measurements were performed at $-0.22 \mathrm{~V}$ versus RHE from $1 \mathrm{MHz}$ to $0.1 \mathrm{~Hz}$ with a $5 \mathrm{mV}$ a.c. amplitude.

482 Device fabrication of $\mathbf{2} \mathbf{H}-\mathrm{NbS}_{2}$ : To demonstrate the HER performance of $2 \mathrm{H}-\mathrm{NbS}$, we carried out HER test using an electrochemical microcell. ${ }^{15}$ We performed e-beam lithography to put gold contacts on as-grown $2 \mathrm{H}-\mathrm{NbS}_{2}$ on $\mathrm{SiO}_{2}(300 \mathrm{~nm})$ substrate. The gold electrodes were deposited via e-beam evaporation under high vacuum conditions $\left(10^{-7}\right.$ Torr $)$. After this process, we performed another e-beam lithography step to open a window on $2 \mathrm{H}-\mathrm{NbS}_{2}$ and cover the gold electrodes to avoid contact with electrolyte. The device is shown in Extended Data Fig. 10.

488 Electrochemical measurements were performed in $0.5 \mathrm{M} \mathrm{H}_{2} \mathrm{SO}_{4}$ and glassy carbon and $\mathrm{Ag} / \mathrm{AgCl}$ electrodes were used as counter and reference electrodes, respectively. 
492 Electrochemical surface area measurements: The estimation of electrochemically active 493 surface area was conducted by measurement of the double-layer capacitance in a potential region 494 with no faradaic response. Cyclic voltammetric (CV) measurements were performed between $495285 \mathrm{mV}$ and $315 \mathrm{mV}$ vs. RHE at various scan rates from $5 \mathrm{mVs}^{-1}$ to $100 \mathrm{mVs}^{-1}$ in order to 496 estimate the double layer capacitance $\left(\mathrm{C}_{\mathrm{dl}}\right)$, see Extended Data Fig. 5. Roughness factor $(\mathrm{RF}) \mathrm{was}$ 497 estimated from the ratio of the measured double layer capacitance with respect to the specific 498 capacitance of glassy carbon electrode $\left(0.87 \mathrm{mF} / \mathrm{cm}^{2}\right)$. Our image analysis of the electrode 499 surface (Extended Data Fig. 4) shows that only 20\% of the glassy carbon electrode is covered 500 by the catalyst. Therefore, to calculate the RF, we take the areal capacitance of the glassy carbon 501 after catalyst deposition to be $\left(0.87 \mathrm{mF}-\mathrm{cm}^{-2}\right)(0.8)=0.7 \mathrm{mF}-\mathrm{cm}^{-2}$. Thus, the RF is given by:

$$
\mathrm{RF}=\frac{9.6 \mathrm{mF} \mathrm{cm}^{-2}}{0.7 \mathrm{mF} \mathrm{cm}-2}=13.7
$$

504 Turnover frequency calculation: According to previous literature, turnover frequency can be 505 obtained following equation.

$$
\operatorname{TOF}\left(s^{-1}\right)=\frac{J\left(\frac{A}{c m^{2}}\right)}{n \times N \times R F \times\left(1.602 \times 10^{-19} C\right)}
$$

506 To determine the density of active sites $(N)$, we assume the lattice constant of $2 \mathrm{H}-\mathrm{Nb}_{1.35} \mathrm{~S}_{2}$ is 3.31 $507 \AA$ (Figure 1c, STEM image). $n$ is the number of electrons involved in the reaction. The surface 508 area of unit cell can be $9.4 \times 10^{-16} \mathrm{~cm}^{2}$. We assumed that entire basal plane can be catalytically 509 active. Therefore, the density of active is estimated to be about $1.06 \times 10^{15} \mathrm{~cm}^{-2}$. The density of 510 the surface active sites of $2 \mathrm{H} \mathrm{Nb}_{1.35} \mathrm{~S}_{2}$ on geometric area : $1.06 \times 10^{15}$ sites $/ \mathrm{cm}^{2} \times 13.7=1.4 \times$ $51110^{16} \mathrm{sites} / \mathrm{cm}^{2}$

512 To get TOF at exchange current density, the exchange current density was extrapolated linearly 513 from the Tafel slope. The exchange current density of $2 \mathrm{H}-\mathrm{Nb}_{1.35} \mathrm{~S}_{2}$ is $800 \mu \mathrm{A} / \mathrm{cm}^{2}$ which is 514 remarkable value among the reported TMD based catalysts as listed in Extended Data Table 1.

516 Electrical conductivity measurements: The conductivity of the intercalated phases was 517 measured and by evaporating gold contacts and is shown in Extended Data Fig. 11. We find the $5182 \mathrm{H} \mathrm{Nb}_{1.35} \mathrm{~S}_{2}$ phase to be highly conducting compared to other reports in the literature. ${ }^{30-33}$ 
520 Computational Methods: The calculations were done using the plane wave density functional 521 theory (DFT) Vienna ab-initio simulation package (VASP) ${ }^{34-37}$ The van der Waals interactions

522 were taken into account at the level of opt-B88 functiona ${ }^{38}$ and the Bayesian error estimation 523 exchange-correlation functional with long-range interactions ${ }^{39}$ (BEEF-vdW). A $500 \mathrm{eV}$ plane524 wave cutoff was used, and the Brillouin zone was sampled with a Monkhorst-Pack ${ }^{40}$ sampling of $5253 \times 3 \times 1$ k-points grid for the relaxation and a $15 \times 15 \times 1$ k-points for the energy calculations. The $526 \Delta \mathrm{G}_{\mathrm{H}}$ were calculated using the formula:

527

$$
\Delta G_{H}=\Delta E+\Delta(Z P E)-T \Delta S
$$

528

529 with

530

$$
\Delta E=E(\operatorname{surface}+H)-E(\operatorname{surface})-\frac{1}{2} E\left(H_{2}\right)
$$

531

$$
\Delta(Z P E)=Z P E_{H}-\frac{1}{2} Z P E_{H_{2}}
$$

532

$$
T \Delta S=\frac{-1}{2} T S_{H_{2}}=-0.205 \mathrm{eV}
$$

535 Where $\mathrm{E}($ surface $+\mathrm{H})$ is the total energy of the system with the $\mathrm{H}$-adatom bound at the basal 536 plane, $\mathrm{E}$ (surface) is the total energy of the pristine system, $\mathrm{E}\left(\mathrm{H}_{2}\right)$ is the total energy of the $\mathrm{H}_{2}$ 537 molecule. $\Delta(\mathrm{ZPE})$ is the difference between the zero-point energy (ZPE) of the H-adatom and the 538 zero-point energy of the $\mathrm{H}_{2}$ molecule, calculated using the normal mode analysis. We will use 539 the entropy of the molecular hydrogen in the gas phase at standard conditions ( 1 bar of $\mathrm{H}_{2}, \mathrm{pH}=0$ 540 and $\mathrm{T}=300 \mathrm{~K}$ ).

541 The bulk lattice parameters calculated using ab initio opt B88-vdW and BEEF-vdW functionals 542 are shown in Extended Data Tables 3 and 5, as well their energetics as displayed in Extended 543 Tables 4, 6, 7 and 8. The corresponding crystal structures obtained from these parameters are 544 shown in Extended Data Figure 12. 
a

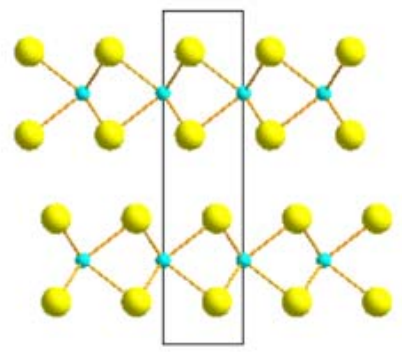

d

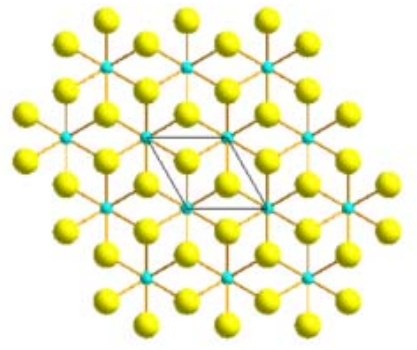

b

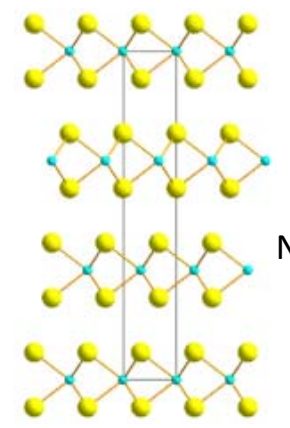

$\mathrm{Nb}$ II (excess)

$\mathrm{Nb} I$

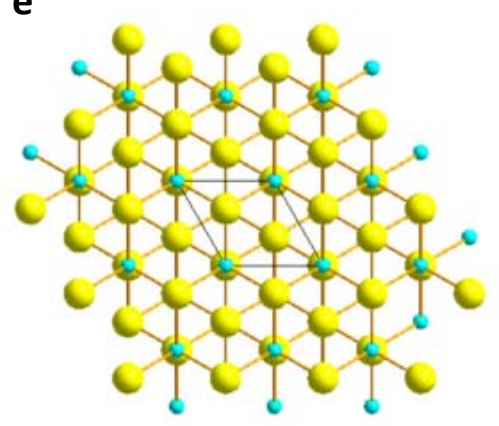

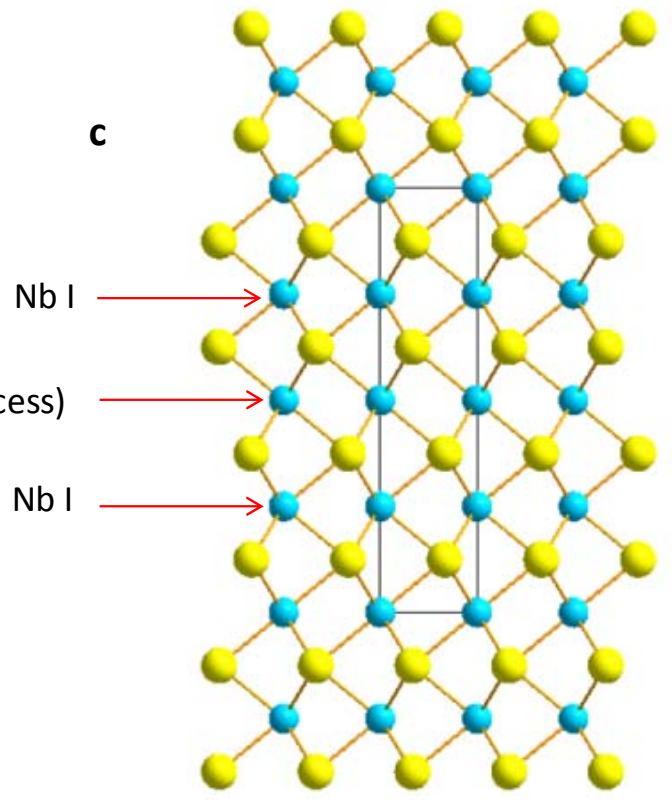

f

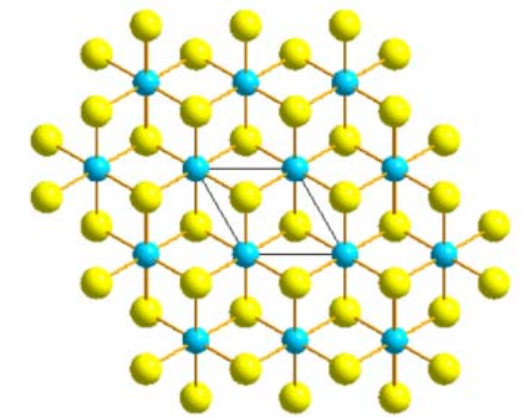

Extended Data Fig. 1 | Phases of $\mathbf{N b S}_{2}$. (a, b) Side view and (d, e) top view of $2 \mathrm{H}$ hexagonal

551 (P63/mmc symmetry) and 3R rhombohedral (R3m symmetry) phases of $\mathrm{NbS}_{2}$. (c, f) Side and top

552 views of $2 \mathrm{H}$ phase $\mathrm{Nb}_{1.35} \mathrm{~S}_{2}$ phase. The excess of $\mathrm{Nb}$ (labelled as $\mathrm{Nb}$ II in the c) occupies

553 octahedral configuration while the $\mathrm{Nb}$ I are in trigonal prismatic sites. The $\mathrm{Nb}_{1.35} \mathrm{~S}_{2}$ phase can

554 also occur in the $3 \mathrm{R}$ phase.

555

556

557

558 

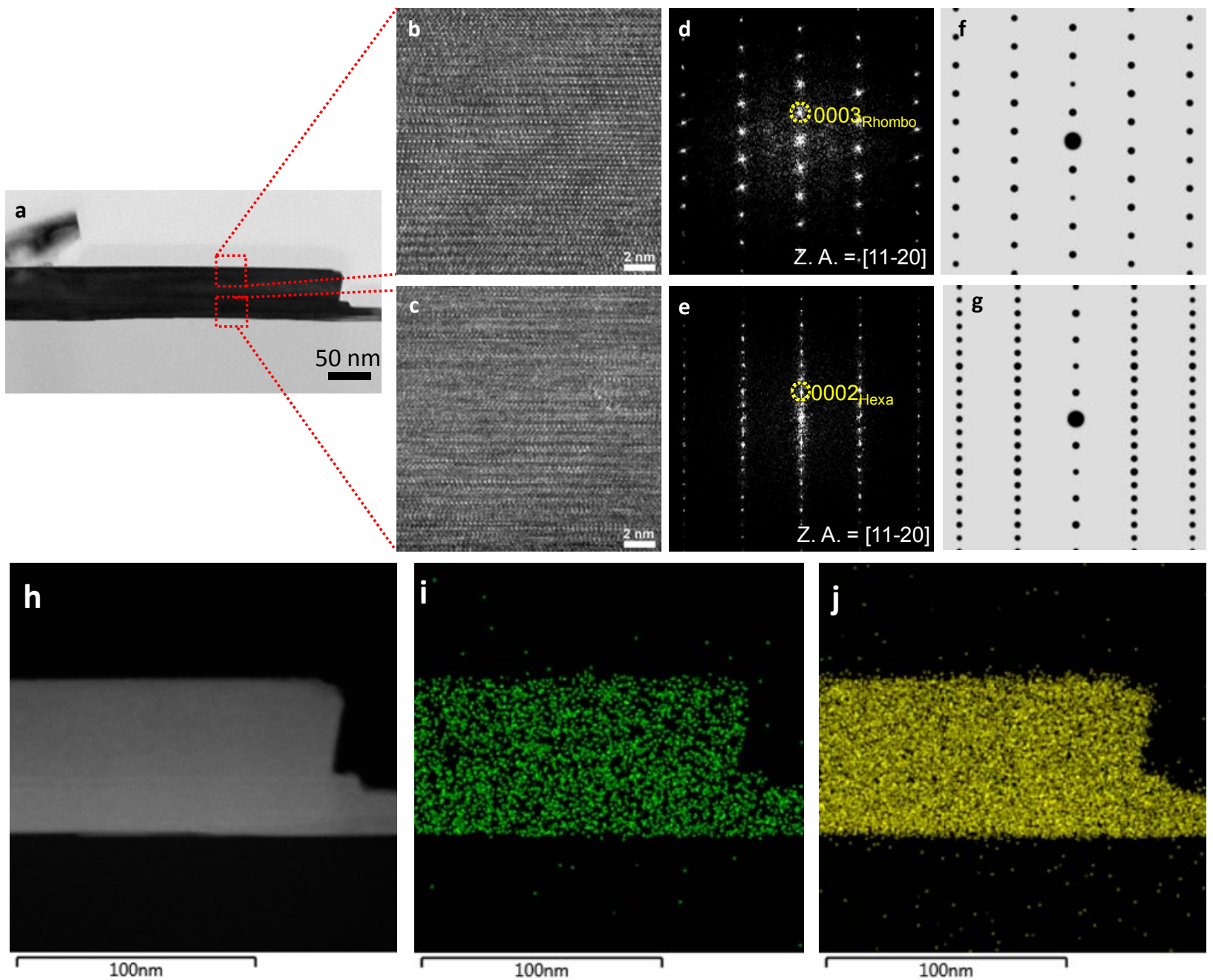

Extended Data Fig. 2 | TEM of $\mathrm{Nb}_{1.35} \mathrm{~S}_{2}$ and corresponding diffraction images. a, Low

564 magnification BFTEM image of cross-sectional FIB sample (thickness $=40 \mathrm{~nm}$ ) prepared from

565 CVD grown samples on $\mathrm{SiO}_{2}$. b, c HRTEM images taken from top of the sample and bottom of

566 the sample as indicated by square dotted regions on the left image. d, e Fast Fourier transform

567 (FFT) pattern indicating that the top (thicker) region is rhombohedral while the bottom (thin)

568 region is in hexagonal configuration based on their very good agreement with simulated patterns

569 shown in $\mathbf{f}$ (simulated ED patterns for intercalated 3R phase) and $\mathbf{g}$ (simulated ED for

570 intercalated $2 \mathrm{H}$ phase). h, Low magnification of image of the FIB cross section and the

571 corresponding Energy Dispersive Spectroscopy map showing $\mathrm{Nb}(\mathbf{i})$ and $\mathrm{S}(\mathbf{j})$ in the sample. 

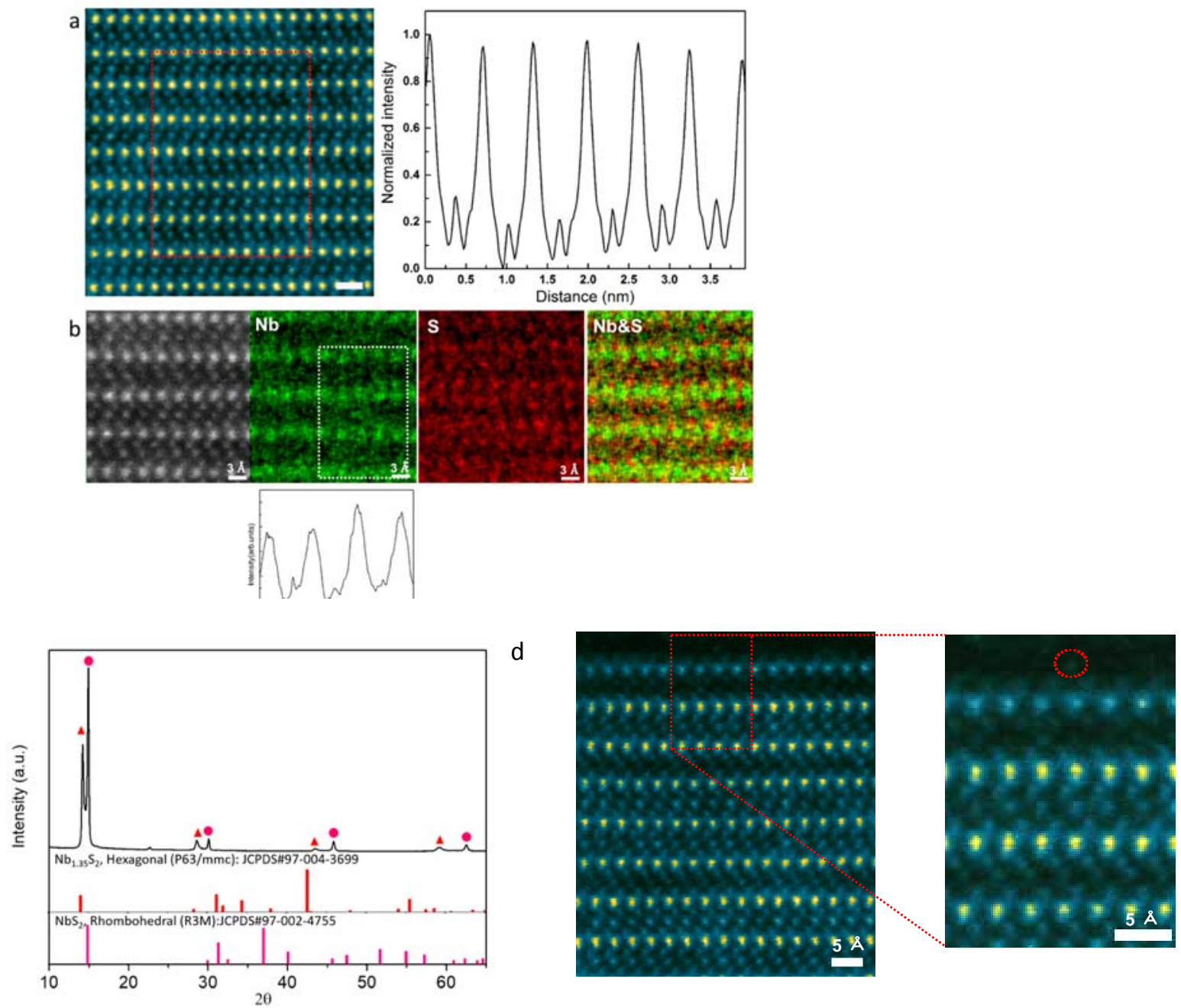

573 Extended Data Fig. 3 | Line scan and chemical analyses in STEM. a, Annular dark field

574 image (left) and the corresponding (right) intensity line scan of $2 \mathrm{H} \mathrm{Nb}_{1.35} \mathrm{~S}_{2}$ phase showing that

$575 \mathrm{Nb}$ atoms are present between the layers. Scale bar $=5 \AA$. b, Black and white unfiltered STEM

576 image and corresponding elemental maps of $\mathrm{Nb}, \mathrm{S}$, and both $\mathrm{Nb}$ and $\mathrm{S}$ obtained using energy

577 dispersive $\mathrm{x}$-ray spectroscopy. The mapping and the line scan below the Nb map confirm that the

578 intercalated atoms are $\mathrm{Nb}$. c, X-ray diffraction of $\mathrm{Nb}_{1.35} \mathrm{~S}_{2}$. The spectrum matches JCPDS\#97-

579 004-3699 for hexagonal phase $\mathrm{Nb}_{1.35} \mathrm{~S}_{2}$, indicated by the triangles. In particular, the presence of 580 additional diffraction peak at $\sim 14.3^{\circ}$ indicates excess $\mathrm{Nb}$. The structure is a combination of 581 layered $\mathrm{NbS} 2$ and intercalated $2 \mathrm{H} \mathrm{Nb}_{1.35} \mathrm{~S}_{2}$ - completely consistent with our STEM results. d, 582 STEM image of $2 \mathrm{H}$ phase $\mathrm{Nb}_{1.35} \mathrm{~S}_{2}$ with an enlargement of the surface region shown on the right. 583 Faint images of $\mathrm{Nb}$ atoms terminating the surface can be observed as indicated by the dotted red 584 circle. 
a

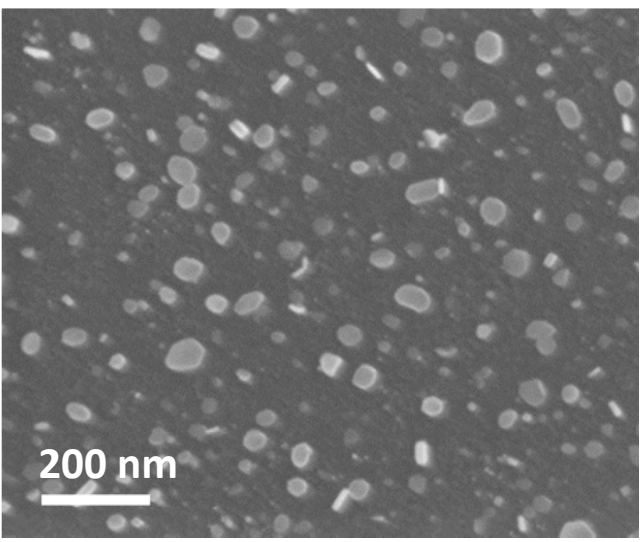

b

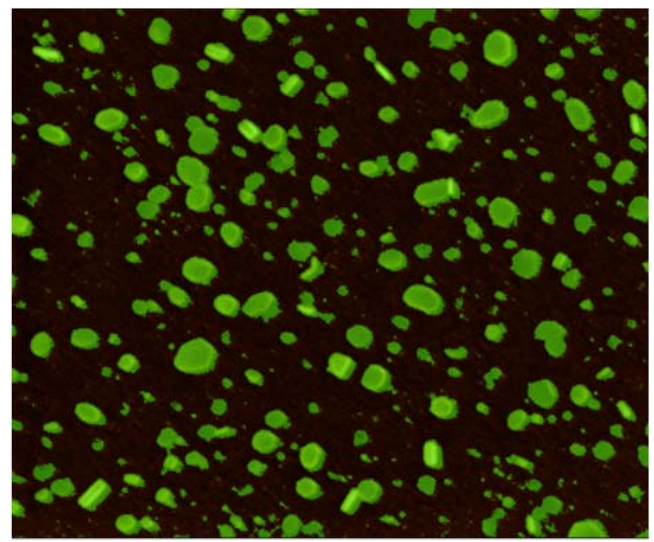

600

Extended Data Fig. 4 | Image analyses of areal coverage of catalysts on electrode surface. a,

601 SEM image of $2 \mathrm{H}-\mathrm{Nb}_{1.35} \mathrm{~S}_{2}$. b, Image analyses was used to highlight (in green) the $\mathrm{Nb}_{1.35} \mathrm{~S}_{2}$

602 flakes on the glassy carbon electrode (black background). Then the percent of area covered by

603 the flakes was calculated. A total of 15 images were taken and the average area covered by the 604 catalyst $\mathrm{Nb}_{1.35} \mathrm{~S}_{2}$ flakes was approximately $20 \% \pm 3 \%$ of the electrode surface.

a

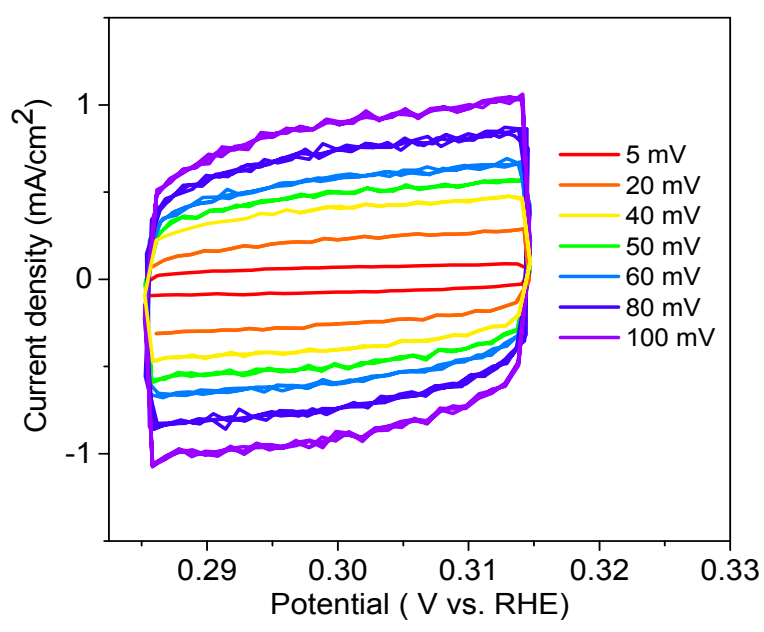

b

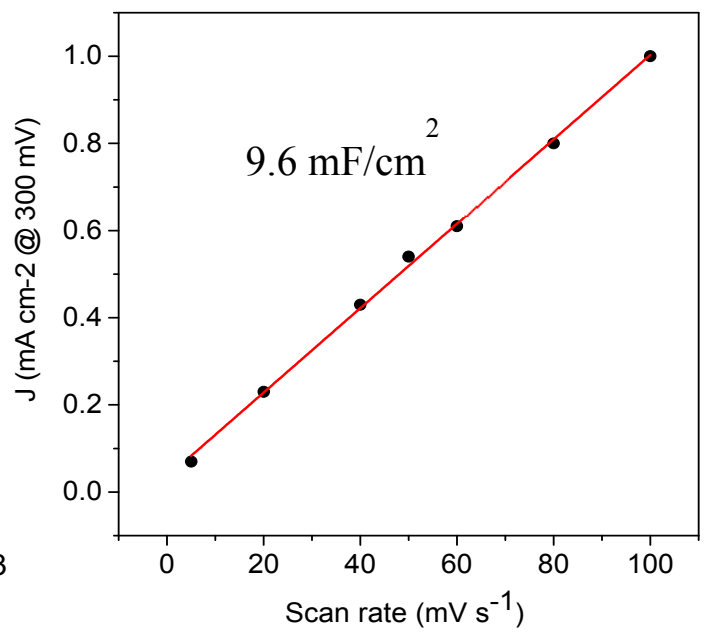

605 
606 Extended Data Fig. 5 | Electrochemical surface area measurements. a, CV curves of $\mathrm{Nb}_{1.35} \mathrm{~S}_{2}$ 607 electrodes measured between 285 and $315 \mathrm{mV}$ vs. RHE. b, Current density at $300 \mathrm{mV}$ plotted 608 against cyclic voltammetry scan rate.

609

610 


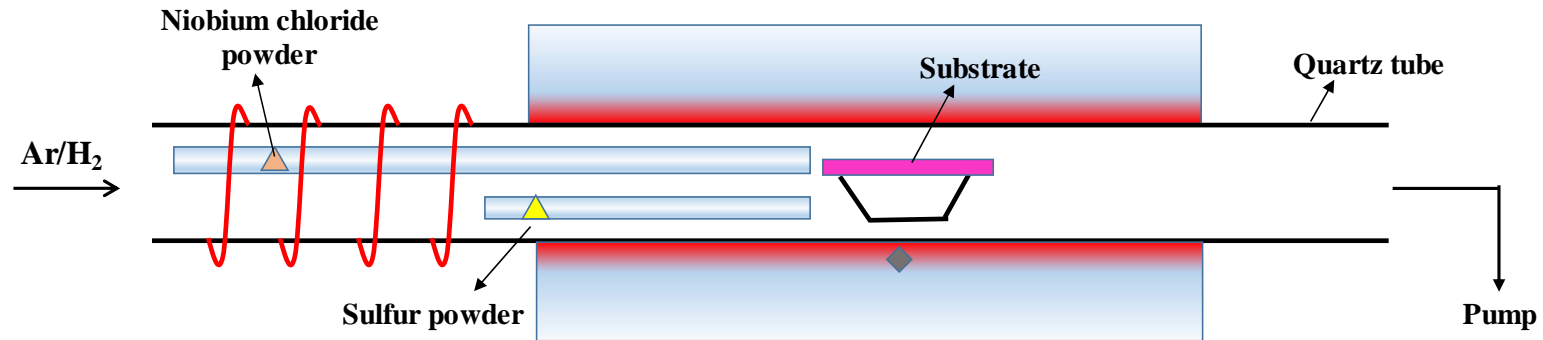

612 Extended Data Fig. 6 | Schematic of chemical vapor deposition setup for $\mathrm{Nb}_{1+\mathrm{x}} \mathrm{S}_{2}$ synthesis.

613 The precursors are placed upstream because they sublimate at a much lower temperature than the 614 growth temperature.

615

616

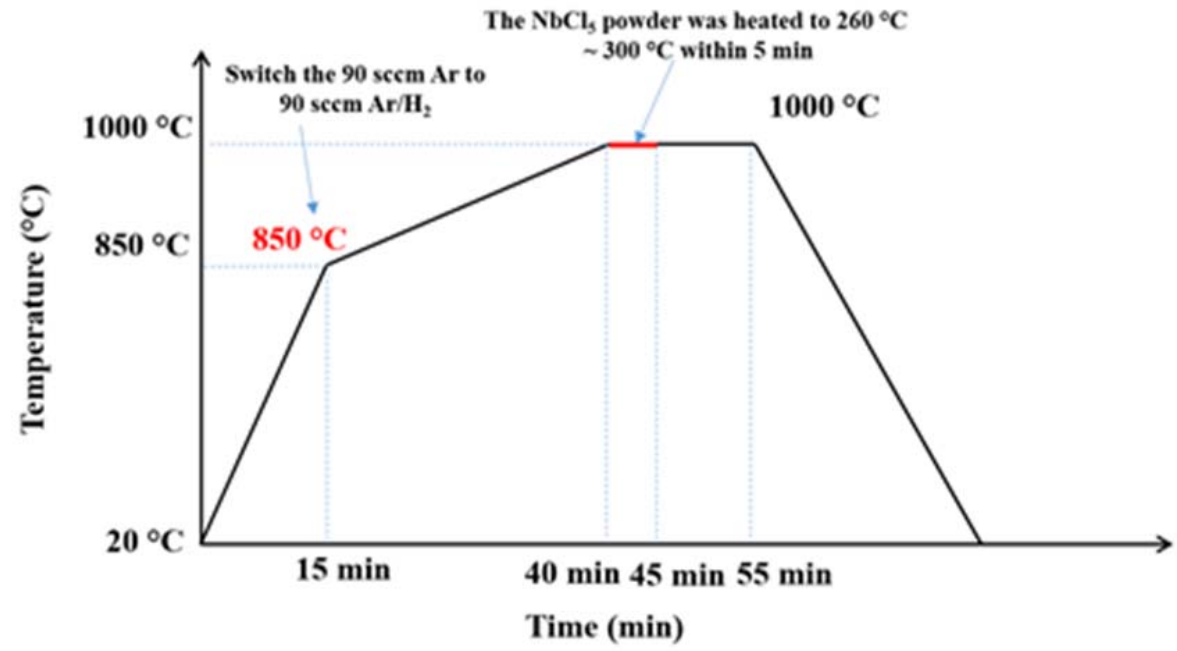

618 Extended Data Fig. 7 | Heating ramp and cooling cycle growth of $\mathbf{N b}_{1+x} \mathbf{S}_{2}$. The tube furnace

619 was initially heated in Ar atmosphere, then in reducing atmosphere and growth was conducted 620 for $10-20$ minutes to achieve different thicknesses.

621

622

623

624 
a

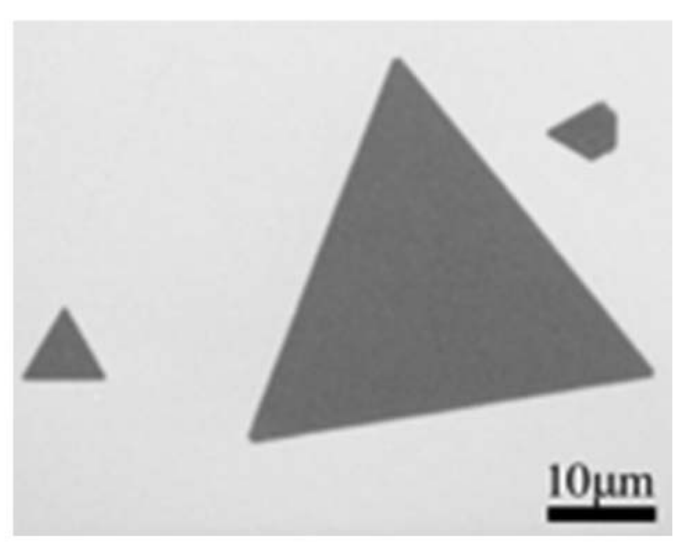

C

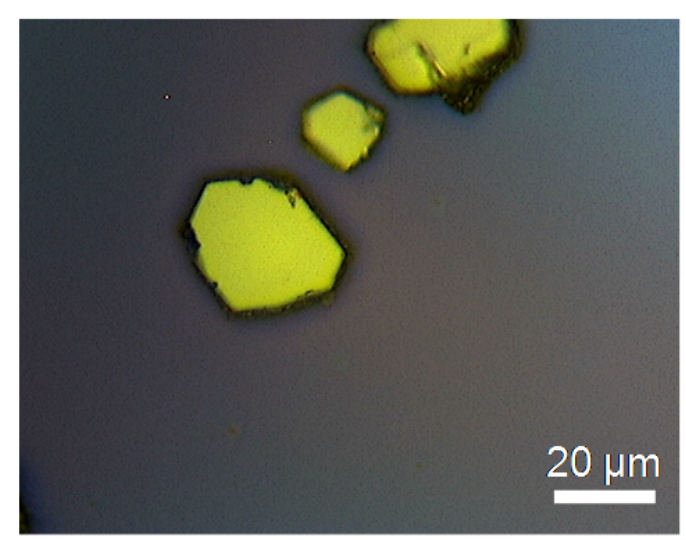

b

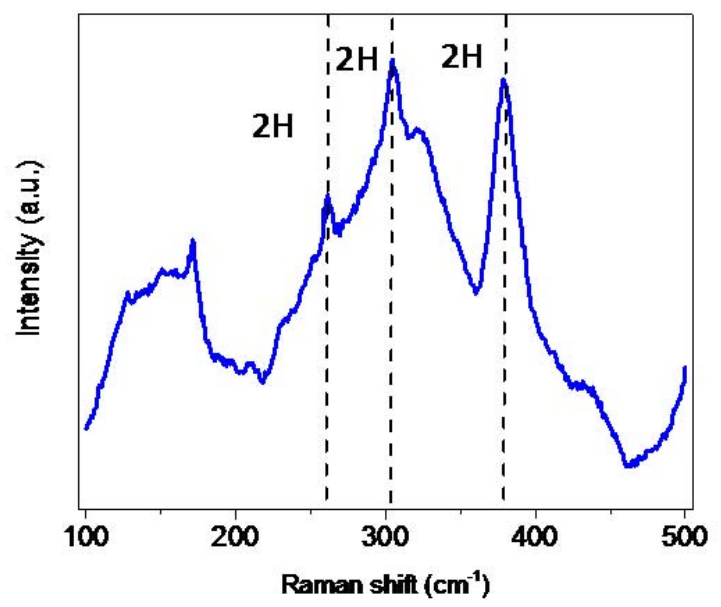

d

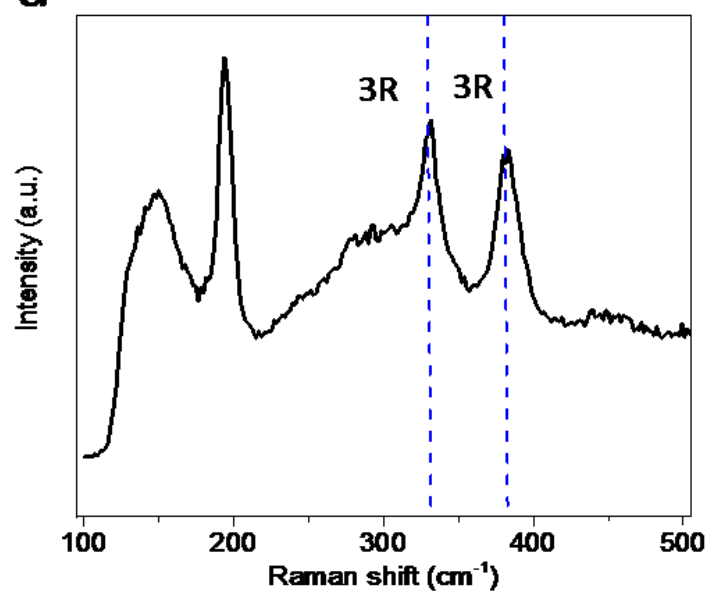

626 Extended Data Fig. 8 | Different phases of $\mathbf{N b S}_{2}$. a, SEM image of CVD grown $2 \mathrm{H}^{-\mathrm{NbS}_{2}}$ with

627 lateral dimensions of 5-20 $\mu \mathrm{m}$ and $\mathbf{b}$, Raman spectrum of $2 \mathrm{H}-\mathrm{NbS}_{2}$ shows $\mathrm{E}_{1 \mathrm{~g},} \mathrm{E}_{1 \mathrm{~g}}^{1}, \mathrm{~A}_{1 \mathrm{~g}}$, at 260 , 628304 and $379 \mathrm{~cm}^{-1}$ respectively. c, Optical microscope image of $3 \mathrm{R}-\mathrm{NbS}_{2}$ grown by CVT and $\mathbf{d}$, 629 Raman spectrum of $3 \mathrm{R}-\mathrm{NbS}_{2}$ shows $\mathrm{E}_{2 \mathrm{~g}}$ and $\mathrm{A}_{1 \mathrm{~g}}$ peaks at $330 \mathrm{~cm}^{-1}$ and $385 \mathrm{~cm}^{-1}$, respectively. 


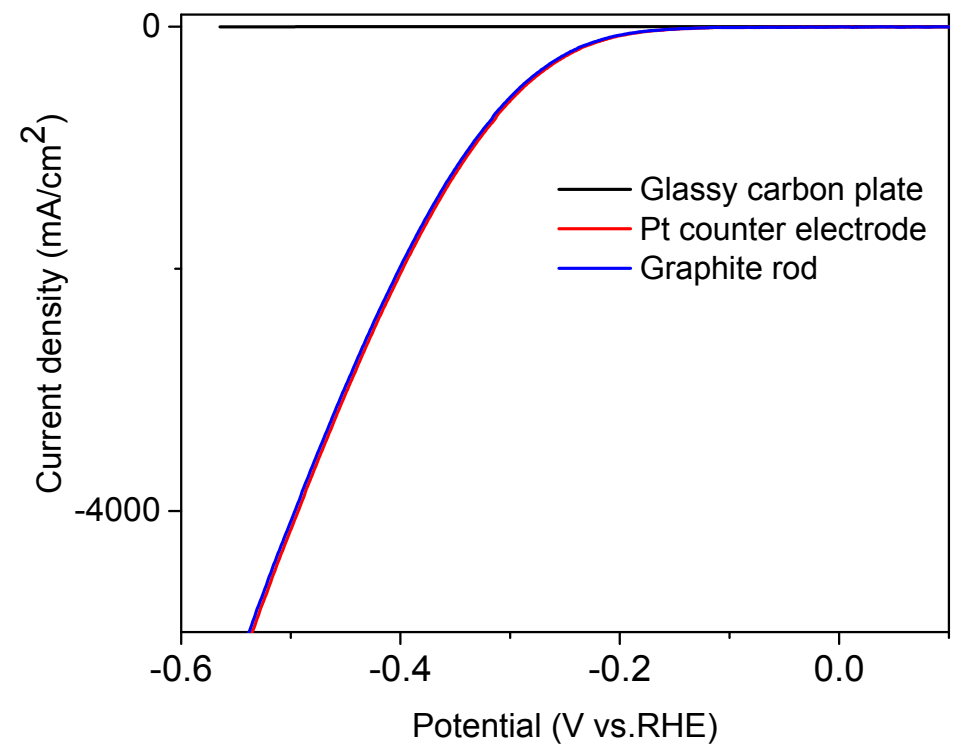

637

638 Extended data Fig. $9 \mid$ Pt vs glassy carbon as counter electrode. Polarization curves for glassy 639 carbon plate and $2 \mathrm{H} \mathrm{Nb}_{1.35} \mathrm{~S}_{2}$ using Pt or carbon as counter electrode.

640

641

642

643

644

645

646

647

648 


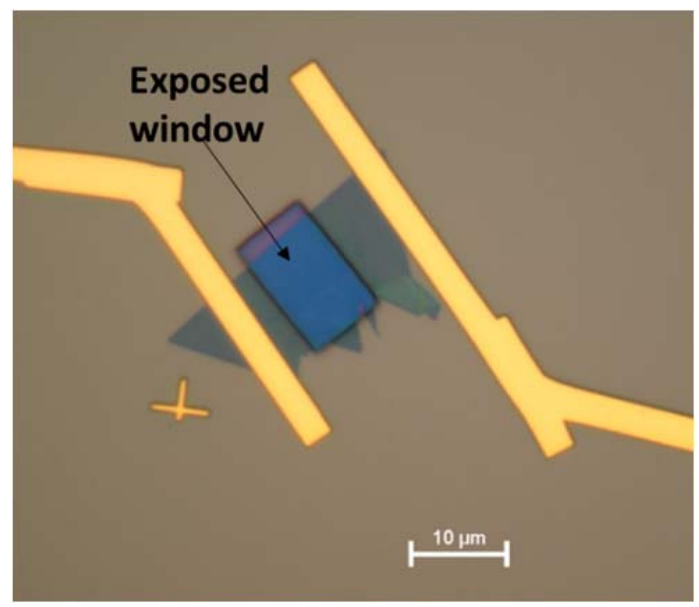

650

651 Extended data Fig. $10 \mid$ Electrochemical microcell devices. Optical image of an 652 electrochemical microcell with $2 \mathrm{H}-\mathrm{NbS}_{2}$ as the catalyst. The blue region is the $\mathrm{NbS}_{2}$ flake and 653 rectangular gold contacts are patterned onto it. A window is opened lithographically so that 654 catalysis measurements can be made. The entire area is covered by PMMA except the window so 655 the electrolyte can only interact with the catalyst.

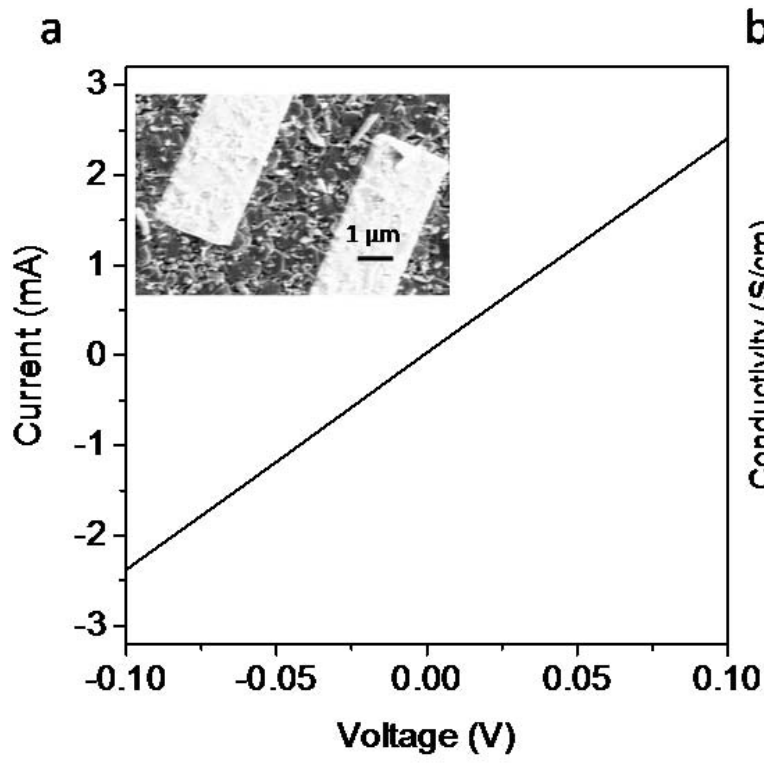

b

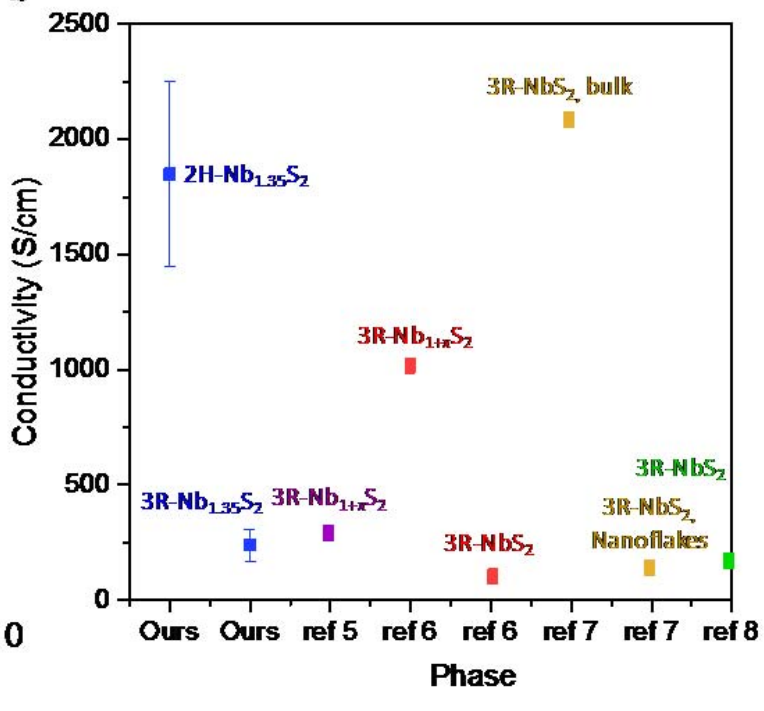

657 Extended data Fig. 11 | Electrical properties of different $\mathbf{N b S}_{2}$. a, I-V curve measured for the $6582 \mathrm{H} \mathrm{Nb}_{1.35} \mathrm{~S}_{2}$ nanoflakes. The inset shows a SEM image of the device. An average value of 1800 $659 \mathrm{~S} / \mathrm{cm}$ was obtained with the highest value being $>2400 \mathrm{~S} / \mathrm{cm}$. b, Comparison of conductivities 660 for $\mathrm{NbS}_{2} . \mathrm{NbS}_{2}$ is known as a metallic TMD material. However, the conductivity values in 661 literature are scattered. ${ }^{30-33}$

662 
664
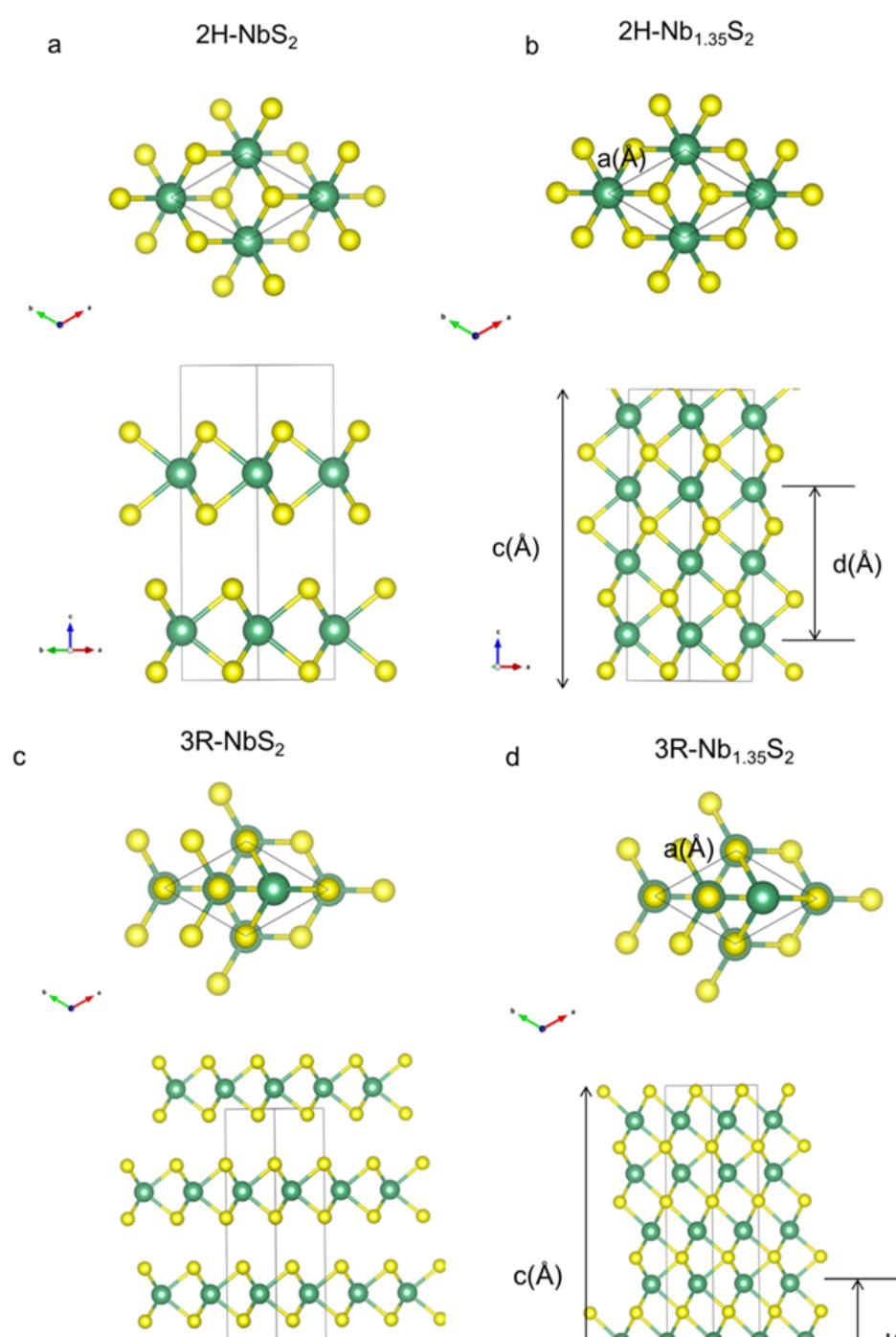

$\stackrel{i}{\rightarrow .}$
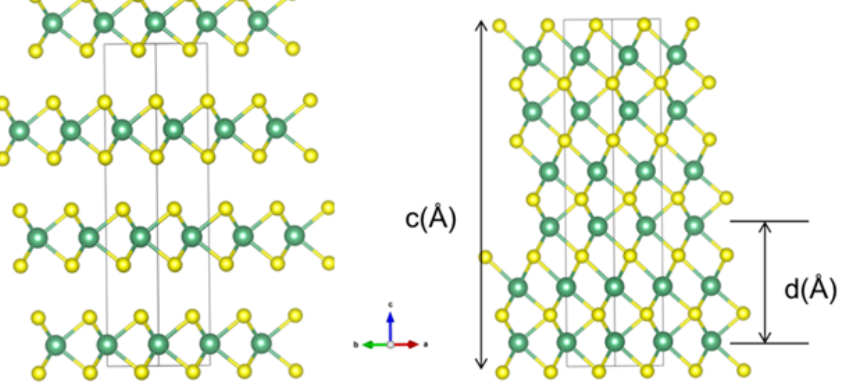

666

667

668 Extended data Fig. $12 \mid$ Definition of geometrical parameters used at Extended Data Table 3 at 669 regular $2 \mathrm{H}-\mathrm{NbS}_{2}$ and $3 \mathrm{R}-\mathrm{NbS}_{2}$ phases as well as in the intercalated $2 \mathrm{H}-\mathrm{Nb}_{1.35} \mathrm{~S}_{2}, 3 \mathrm{R}-\mathrm{Nb}_{1.35} \mathrm{~S}_{2}$ 670 phases.

671 
a

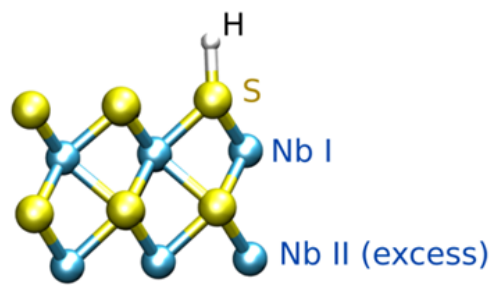

$\mathrm{H}-\mathrm{S}$ adsorption b

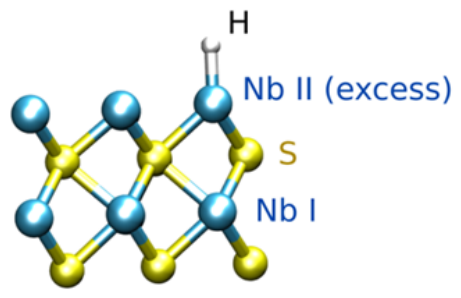

$\mathrm{H}-\mathrm{Nb}$ adsorption

672

673

674

675

676

677

678

679

680

681

682

683

684

$$
\begin{gathered}
2 \mathrm{H}-\mathrm{Nb}_{1.35} \mathrm{~S}_{2} \\
2 \mathrm{H}-\mathrm{MoS}_{2} / \mathrm{Au} \\
1 \mathrm{~T}-\mathrm{WS}_{2} \\
2 \mathrm{H}-\mathrm{TaS}_{2}
\end{gathered}
$$

$\mathrm{Pt}$

$\boldsymbol{J}_{\mathbf{0}}\left(\boldsymbol{\mu} \boldsymbol{A} / \mathbf{c m}^{2}\right)$
$800 \pm 100$
7.9
20
$100-179.47$
450

$\begin{array}{cc}\text { TOF at } \boldsymbol{J}_{\boldsymbol{0}} & \text { ref } \\ 0.17 \mathrm{~s}^{-1} \pm 0.03 & \text { Our work } \\ - & 9 \\ 0.043 & 3 \\ - & 5 \\ 0.9 & 9\end{array}$

685

686

687

688

689

690

691

692

693 
694 Extended Data Table 3 | Bulk lattice parameters using opt-B88 functional. Simulations of 695 the geometrical parameters using opt-B88 functional including vdW interactions. Lattice 696 parameter, $\mathrm{a}(\AA)$, interlayer distance via $\mathrm{Nb}-\mathrm{Nb}$ distance, $\mathrm{d}(\AA)$, and supercell length, $\mathrm{c}(\AA)$ are 697 defined as in Extended Data Figure 12. Sound comparison with experimental data at different 698 phases is observed.

\begin{tabular}{|c|c|c|c|c|c|c|c|}
\hline & \multicolumn{2}{|c|}{$2 \mathrm{H}-\mathrm{NbS}_{2}$} & \multicolumn{2}{c|}{$3 \mathrm{R}-\mathrm{NbS}_{2}$} & \multicolumn{2}{c|}{$2 \mathrm{H}-\mathrm{Nb}_{1.35} \mathrm{~S}_{2}$} & $3 \mathrm{R}_{2}-\mathrm{Nb}_{1.35} \mathrm{~S}_{2}$ \\
\hline & Theory & Exp. & Theory & Exp. & Theory & Exp. & Theory \\
\hline $\mathrm{a}(\mathrm{)})$ & 3.34 & 3.31 & 3.35 & 3.33 & 3.31 & 3.306 & 3.24 \\
\hline $\mathrm{d}(\mathrm{r})$ & 5.97 & 5.91 & 6.05 & 5.98 & 6.64 & 6.35 & 6.81 \\
\hline $\mathrm{c}(~)$ & 11.935 & 11.89 & 18.17 & 17.81 & 13.29 & 12.6 & 20.43 \\
\hline
\end{tabular}

699

700

701

702

703

704

705

706

707

708

709

710

711

Extended Data Table 4 | Thermodynamic properties of $\mathrm{S}$ terminated surface using opt-B88

functional. Energetics of the intercalated phase $2 \mathrm{H}-\mathrm{Nb}_{1.35} \mathrm{~S}_{2}$ with adsorption of $\mathrm{H}$ at $\mathrm{S}$ atoms at different coverages using opt-B88 functional. The large values of $\Delta \mathrm{G}_{\mathrm{H}}(\mathrm{eV})$ at different coverages rule out any HER using S-terminate surfaces.

\begin{tabular}{|c|c|c|c|}
\hline & \multicolumn{3}{|c|}{$2 \mathrm{H}-\mathrm{Nb}_{1.35} \mathrm{~S}_{2}(\mathrm{H}-\mathrm{S}$ adsorption $)$} \\
\hline Coverage & $0.11 \mathrm{ML}$ & $0.25 \mathrm{ML}$ & $1 \mathrm{ML}$ \\
\hline$\Delta \mathrm{E}(\mathrm{eV})$ & 1.011 & 0.804 & 1.459 \\
\hline $\mathrm{ZPE}(\mathrm{eV})$ & 0.203 & 0.203 & 0.162 \\
\hline$\Delta \mathrm{G}_{\mathrm{H}}(\mathrm{eV})$ & 1.245 & 1.077 & 1.694 \\
\hline
\end{tabular}

Extended Data Table 5 | Bulk lattice parameters using BEEF-vdW functional. Simulations of the geometrical parameters using BEEF-vdW functional including vdW interactions. Lattice parameter, $\mathrm{a}(\AA)$, interlayer distance via $\mathrm{Nb}-\mathrm{Nb}$ distance, $\mathrm{d}(\AA)$, and supercell length, $\mathrm{c}(\AA)$ are defined as in Extended Data Figure 12. Sound comparison with experimental data at different phases is obtained.

\begin{tabular}{|c|c|c|c|c|c|c|c|}
\hline & \multicolumn{2}{|c|}{$2 \mathrm{H}_{-} \mathrm{NbS}_{2}$} & \multicolumn{2}{c|}{$3 \mathrm{R}-\mathrm{NbS}_{2}$} & \multicolumn{2}{c|}{$2 \mathrm{H}-\mathrm{Nb}_{1.35} \mathrm{~S}_{2}$} & $3 \mathrm{R}_{2}-\mathrm{Nb}_{1.35} \mathrm{~S}_{2}$ \\
\hline & Theory & Exp. & Theory & Exp. & Theory & Exp & Theory \\
\hline $\mathrm{a}(\mathrm{)})$ & 3.35 & 3.31 & 3.35 & 3.33 & 3.30 & 3.30 & 3.22 \\
\hline $\mathrm{d}(\mathrm{)})$ & 6.34 & 5.91 & 6.36 & 5.98 & 6.65 & 6.35 & 6.65 \\
\hline $\mathrm{c}(\mathrm{)})$ & 12.67 & 11.89 & 19.10 & 17.81 & 13.30 & 12.6 & 19.94 \\
\hline
\end{tabular}


713 Extended Data Table 6 | Thermodynamic properties of S terminated surface using BEEF-

$714 \mathbf{v d W}$ functional. Energetics of the intercalated phases $2 \mathrm{H}-\mathrm{Nb}_{1.35} \mathrm{~S}_{2}$ and $3 \mathrm{R}-\mathrm{Nb}_{1.35} \mathrm{~S}_{2}$ with 715 adsorption of $\mathrm{H}$ at $\mathrm{S}$ atoms at different coverages using BEEF-vdW functional. Similarly as in 716 the opt-B88 functional, the S-terminated surface seems inert for HER as long as $\mathrm{H}$ atoms bind on $717 \mathrm{~S}$.

\begin{tabular}{|c|c|c|c|c|}
\hline & \multicolumn{3}{|c|}{$\begin{array}{c}2 \mathrm{H}-\mathrm{Nb}_{1.35} \mathrm{~S}_{2} \\
(\mathrm{H}-\mathrm{S} \text { adsorption })\end{array}$} & $\begin{array}{c}3 \mathrm{R}-\mathrm{Nb}_{1.35} \mathrm{~S}_{2} \\
\text { (H-S adsorption) }\end{array}$ \\
\hline Coverage & $0.11 \mathrm{ML}$ & $0.25 \mathrm{ML}$ & $1 \mathrm{ML}$ & $0.25 \mathrm{ML}$ \\
\hline$\Delta \mathrm{E}(\mathrm{eV})$ & 1.005 & 0.766 & 1.41 & 0.619 \\
\hline $\mathrm{ZPE}(\mathrm{eV})$ & 0.226 & 0.226 & 0.16 & 0.226 \\
\hline$\Delta \mathrm{G}_{\mathrm{H}}(\mathrm{eV})$ & 1.302 & 0.989 & 1.64 & 0.915 \\
\hline
\end{tabular}

Extended Data Table 7 | Thermodynamic properties of a monolayer $\mathrm{NbS}_{2}$ with additional

$721 \mathrm{Nb}$ atoms in the structure. Energetics of the monolayer $\mathrm{NbS}_{2}$ with additional $\mathrm{Nb}$ atoms

722 incorporated into the structure (see Extended Data Fig. 13). This system corresponds to the 723 smallest situation where the effect of additional $\mathrm{Nb}$ atoms could be appreciated on the free 724 energies and HER of monolayer $\mathrm{NbS}_{2}$. The adsorption of $\mathrm{H}$ is simulated either at S-terminated 725 the surface or at $\mathrm{Nb}$-terminated. The large variations in energy between both configurations 726 indicate the $\mathrm{H}$ adatoms would prefer binding at the $\mathrm{Nb}$ sites rather than on $\mathrm{S}$. This suggests that 727 additional $\mathrm{Nb}$ atoms have a strong effect on the chemical kinetics of the reaction changing the 728 preferable site of $\mathrm{H}$ adsorption for efficient HER. Similar results as those in Ref. 22 are 729 compared for the monolayer $\mathrm{NbS}_{2}$ without additional $\mathrm{Nb}$ atoms. Calculations at the level of 730 BEEF-vdW functional.

\begin{tabular}{|c|c|c|c|}
\hline & Monolayer $\mathrm{NbS}_{2}$ & $\begin{array}{c}\text { Monolayer } \mathrm{NbS}_{2} \\
\text { Nb terminated } \\
\text { (H-S adsorption) }\end{array}$ & $\begin{array}{c}\text { Monolayer } \mathrm{NbS}_{2} \\
\text { Nb terminated } \\
\text { (H-Nb adsorption) }\end{array}$ \\
\hline Coverage & $0.0625 \mathrm{ML}$ & $0.25 \mathrm{ML}$ & $0.25 \mathrm{ML}$ \\
\hline$\Delta \mathrm{E}(\mathrm{eV})$ & -0.185 & 1.039 & 0.072 \\
\hline $\mathrm{ZPE}(\mathrm{eV})$ & 0.226 & 0.215 & 0.098 \\
\hline$\Delta \mathrm{G}_{\mathrm{H}}(\mathrm{eV})$ & 0.11 & 1.324 & 0.24 \\
\hline
\end{tabular}


733 Extended Data Table 8 | Thermodynamic properties of Nb terminated slab with adsorption

734 of $\mathbf{H}$ on $\mathbf{N b}$ atoms. Energetics of the intercalated phases $2 \mathrm{H}-\mathrm{Nb}_{1.35} \mathrm{~S}_{2}$ and $3 \mathrm{R}-\mathrm{Nb}_{1.35} \mathrm{~S}_{2}$ with 735 adsorption of $\mathrm{H}$ on $\mathrm{Nb}$ atoms using BEEF-vdW functional. The resulting geometries are those 736 shown in Figure 4. The comparison between $2 \mathrm{H}-\mathrm{Nb}_{1.35} \mathrm{~S}_{2}$ and $3 \mathrm{R}-\mathrm{Nb}_{1.35} \mathrm{~S}_{2}$ clearly indicates that 737 the former would give better HER results than the latter, as it follows closely the measurements.

\begin{tabular}{|c|c|c|}
\hline & $2 \mathrm{H}-\mathrm{Nb}_{1.35} \mathrm{~S}_{2}(\mathrm{Nb}$ Terminated $)$ & $3 \mathrm{R}-\mathrm{Nb}_{1.35} \mathrm{~S}_{2}(\mathrm{Nb}$ Terminated $)$ \\
\hline Coverage & $0.25 \mathrm{ML}$ & $0.25 \mathrm{ML}$ \\
\hline$\Delta \mathrm{E}(\mathrm{eV})$ & -0.056 & 0.066 \\
\hline $\mathrm{ZPE}(\mathrm{eV})$ & 0.099 & 0.098 \\
\hline$\Delta \mathrm{G}_{\mathrm{H}}(\mathrm{eV})$ & 0.11 & 0.235 \\
\hline
\end{tabular}

742 28. Li, S. et al. Halide-assisted atmospheric pressure growth of large WSe2 and WS2 743 monolayer crystals. Appl. Mater. Today 1, 60-66 (2015).

744 29. Suh, J. et al. Doping against the Native Propensity of MoS2: Degenerate Hole Doping by 745 Cation Substitution. Nano Lett. 14, 6976-6982 (2014).

746 30. Huang, Y. H., Peng, C. C., Chen, R. S., Huang, Y. S. \& Ho, C. H. Transport properties in 747 semiconducting NbS2 nanoflakes. Appl. Phys. Lett. 105, 93106 (2014).

748 31. Molenda, J., Bak, T. \& Marzec, J. Electrical and electrochemical properties of niobium 749 disulphide. Phys. Status Solidi A 156, 159-168 (1996).

750 32. Niazi, A. \& Rastogi, A. K. Low-temperature resistance minimum in non-superconducting 751 3R-Nb 1+ x S 2 and 3R-Ga x NbS 2. J. Phys. Condens. Matter 13, 6787 (2001).

752 33. Zhao, S. et al. Two-dimensional metallic NbS 2 : growth, optical identification and 753 transport properties. 2D Mater. 3, 25027 (2016). 
754 34. Kresse, G. \& Hafner, J. Ab initio molecular dynamics for liquid metals. Phys. Rev. B 47, $755 \quad 558-561(1993)$.

756 35. Kresse, G. \& Hafner, J. Ab initio molecular-dynamics simulation of the liquid-

757 metal $\backslash c h a r 21\{\}$ amorphous-semiconductor transition in germanium. Phys. Rev. B 49, 14251$758 \quad 14269(1994)$.

759 36. Kresse, G. \& Furthmüller, J. Efficiency of ab-initio total energy calculations for metals 760 and semiconductors using a plane-wave basis set. Comput. Mater. Sci. 6, 15-50 (1996).

761 37. Kresse, G. \& Furthmüller, J. Efficient iterative schemes for ab initio total-energy

762 calculations using a plane-wave basis set. Phys. Rev. B 54, 11169-11186 (1996).

763 38. Klimeš, J., Bowler, D. R. \& Michaelides, A. Chemical accuracy for the van der Waals

764 density functional. J. Phys. Condens. Matter 22, 22201 (2010).

765 39. Wellendorff, J. et al. Density functionals for surface science: Exchange-correlation model 766 development with Bayesian error estimation. Phys. Rev. B 85, 235149 (2012).

767 40. Monkhorst, H. J. \& Pack, J. D. Special points for Brillouin-zone integrations. Phys. Rev. 768 B 13, 5188-5192(1976).

769

770

771 